


\title{
POWER FARMING
}

\author{
BY \\ RAYMONDOLNEY \\ Pozur-Farming kixpert
}

THIS IS THE FIRST COMPLETE TALK ON HOW TO DO FARMING WITH A TRACTOR AND What TO do IT With. STUdY THIS AND You CAN MAKE A Success With Your OUTFit. The Material FOUND in THESE PAgEs is BASEd ON THE Practical Experience of Men Who Have Made GOOD. MAKING GOOD WITH A TRACTOR MEANS MAKING MONEY

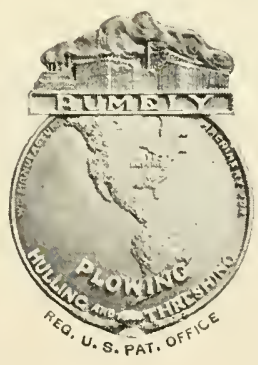

M. RUMELY COMPANY

LaPORTE, IND., U.S. A. 
Copyright 1913 by M. RUMELY COMPANY

LaPorte, Ind., U. S. A. 


\section{POWER FARMING Profits and Equipment}

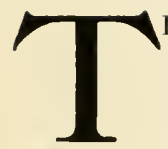

HAT which the power farmer works hardest for is profits. His whole energy is bent on increasing his labor income. His chief aim is to produce bigger and better crops at a decreased cost. But to accomplish a high percentage of results requires the best equipment that he can provide for his business of farming.

The average farmer is too often at a big disadvantage because of a lack of good equipment for carrying on his farm work. He knows that no matter how rich the soil, how good the seed, or how favorable weather conditions may be, he can do nothing without power and implements. They are essential.

It is a big saving to have the right kind of "equipment and a supply sufficient to perform the different operations properly. It solves to a very large extent one of the great farm problems-labor. The increased use of labor-saving machines has largely cut down the amount of man labor which is required on every farm. Also, it has made it possible for each worker to accomplish more work. It has increased his working capacity and has made him more efficient. Instead of a large crew of hired men, the farmer and his boys can do most of the work themselves and do it easier.

By giving more attention to decreasing the cost of producing crops the farmer will find surer and bigger profits than he will from high market prices. In other words, he should not depend entirely for his profits on the high prices he may or may not get when he markets his products, but rather the most sensible and profitable thing for him to do is to give most of his attention to cutting down the overhead charges. He should make his profits doubly sure by cutting down the expense of production.

The fundamental importance of farm machinery is that it enables the farmer to produce his crops with less expense, and it also makes it possible for him to handle a much larger acreage. Agricultural authorities have proved that increased crop yields depend upon three essentials: Seed, soil and thorough tillage. Thorough tillage, which is doubtless the most important, absolutely depends on power and machinery.

The general-purpose farm tractor has in a sense made it necessary for the farmer to buy more equipment, but at the same time it has decreased in a much larger proportion the cost of producing the crops. It has increased the usefulness of each machine and though in the first place it involves a large investment, the farmer should nevertheless provide himself with sufficient tools to perform his work properly. It is nothing more or less than a matter of good business management.

Manufacturers have been slow to build farm machinery which can readily be used behind the tractor. Excepting the engine gang plow, the machines are practically the same as those which were designed for use with horses. In order to load the engine to its normal, full-load capacity and do more work in a given space of time, it is necessary to haul a number of machines at one time, for example; discs, harrows, drills, seeders, packers, binders, etc. For this purpose, hitches have been designed and built, by the use of which the farmer can haul as many implements to good advantage as the tractor will pull.

The farmer should at all times have the thought of the biggest profits foremost in his mind. At the same time he should not forget that a large income is not possible without good equipment. The best results depend directly upon the machines used and the intelligence exercised in selecting and using them to get the most out of the investment. 


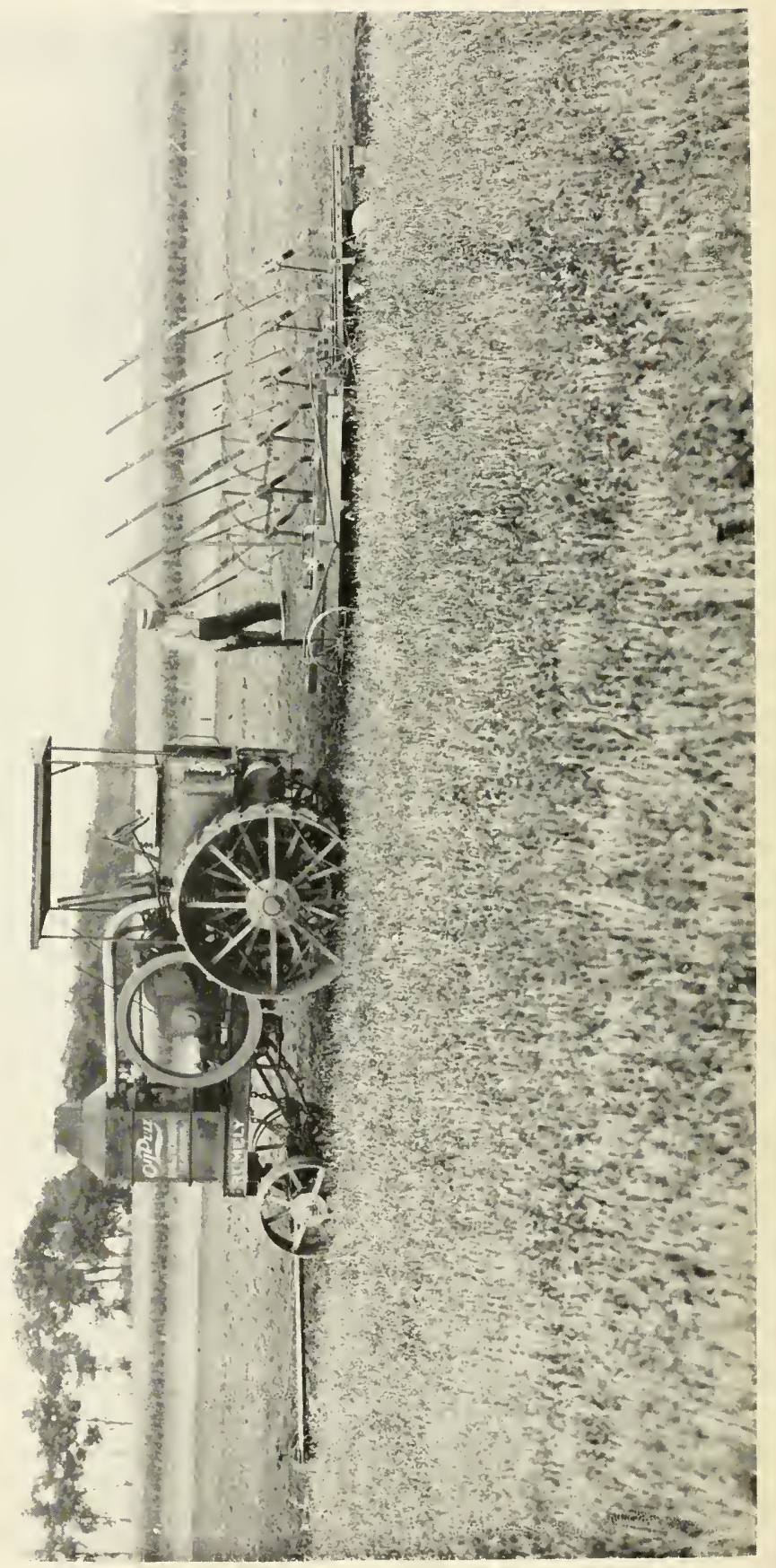




\section{How to Farm With a Tractor}

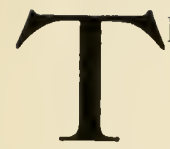

HE first and most important essential in farming with a tractor is good business management. It is just as necessary in farming as it is in any manufacturing or business undertaking. It is even more so, in fact, because of the large amount of equipment that is required to carry on the farm work. A larger number and a greater variety of machines are needed on the farm than in any other industry compared to its size. Without good and sufficient equipment the farmer is very seriously handicapped. It is to his advantage to have the best machines which money can buy, but it takes a first-class manager to get the most out of the investment. He must have energy and ability to succeed.

\section{SELECTING THE TRACTOR AND OTHER MACHINES}

The first and most important part of the power-farming equipment is the tractor. The prospective purchaser should be very careful in buying

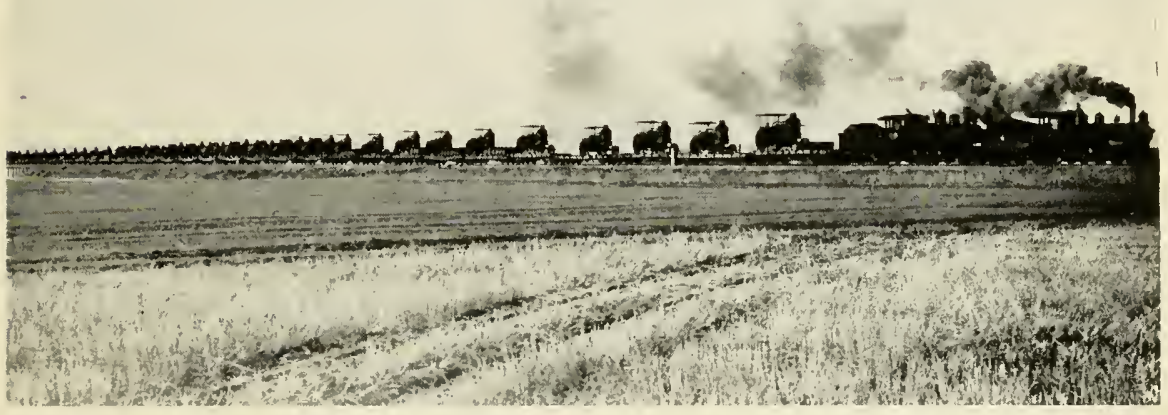

THE BIGGEST SHIPMENT OF AGRICULTURAL MACHINERY (Fig. 1)

This trainload consists of 101 Rumely OilPull Tractors, 81 Rumely Separators and 139 Rumely kerosene tanks. It impresses one with the idea that the farm tractor is rapidly coming into use for replacing horses to a large extent on our farms.

his engine to see that he gets one which will be best adapted to his own particular conditions. It is always well to invest with a reliable manufacturing concern so as to be sure of getting a good machine. Above all things;

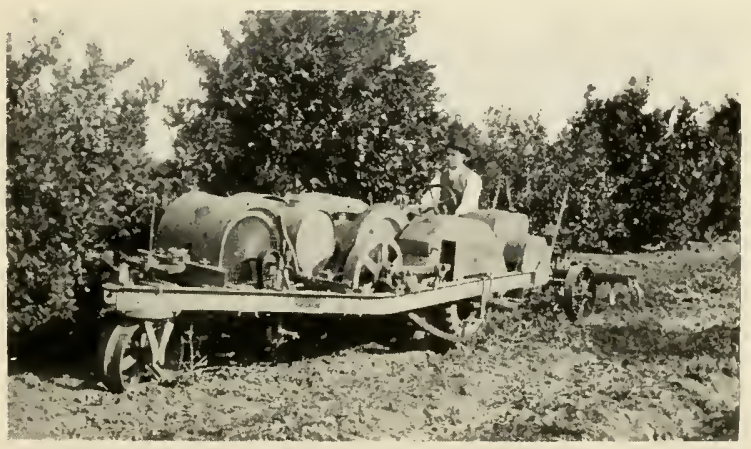

CULTIVATING THE ORCHARD (Fig. 2)

The Rumely ToeHold Tractor is ideally adapted for orchard and cultivating work and for use on the smaller farms. 
insist upon quality. Rather let the price be a secondary consideration. By getting the best it will always be found to pay in the long run.

The tractor is the unit which furnishes the power for hauling all the other machines. Therefore, these implements should also be selected on a basis of quality, and at the same time they should be of such a design and construction to work well with the engine.

When making an investment in machinery, it is an unwise plan to limit the efficiency of the tractor by a lack of equipment. While it may seem at times that the investment required is too great, still the farmer should always have enough machines to make up a full load for his tractor. It has been found that the greatest economy can be obtained when it is loaded to its normal capacity.

\section{AUXILIARY EQUIPMENT.}

Aside from the various implements which are necessary to the equipment, there is a certain amount of auxiliary apparatus such as repair parts, tools,

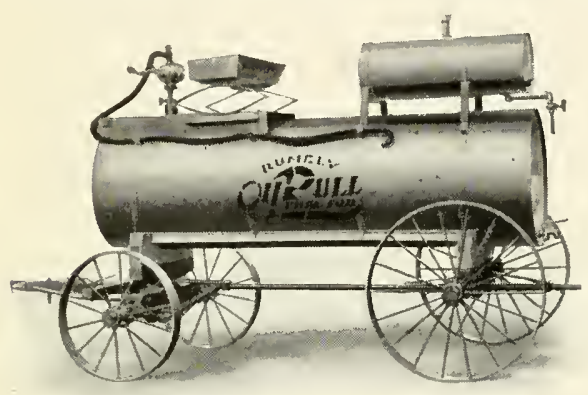

RUMELY OIL TANK WAGON (Fig. 3)

An oil tank wagon is an essential part of the power farmer's equipment. A large quantity can be hauled from town at one time. It is also very useful when the engine is working some distance from the source of supplies. If kerosene is used as fuel, the small tank on top is filled with gasoline for starting the engine. oil and water tanks, chains, clevises, extra bolts, etc., which should be with every tractor outfit. A blacksmith's outfit is a very desirable thing to have, and it can frequently be used to good advantage when a shop is miles away. In times of emergency, when every minute counts, this auxiliary apparatus will be a means of saving considerable time in repairing breakages or replacing lost parts.

When working in extra large fields at a considerable distance away from headquarters, it is a good thing to provide eating and sleeping quarters for the men so that no time will be lost in traveling to and from the work. The men will have more time to care for the outfit outside of working hours and they will find it easier work all around. On the smaller farms this is not necessary as the time lost in going to and from the fields is very small. In this case it is an advantage to have the headquarters located at the farm buildings where the fuel and other supplies are stored, as filling tanks, repairing and overhauling can be done much easier there than in the field.

\section{QUALITY BEFORE QUANTITY}

In many cases, there is a decided tendency for men owning tractor outfits to attempt to farm on a large scale. It seems to be the opinion that they can make more money by tilling these large areas, even though the work is slovenly in character. It should be borne in mind that a few acres of welltilled land will bring greater returns than a large number of acres where the work is slighted. While the tractor does enable the farmer to cultivate a larger acreage than he can with the equivalent number of horses, still he should not sacrifice quality for quantity. His engine enables him to secure greater quality than he can with horses because of the fact that the power is concentrated, and intensive farming can be practiced equally as well as 
extensive farming. Power farming should be synonymous with intensive farming.

With the best engine and equipment the farmer can do better work. But he should not lose sight of the fact that it is absolutely necessary to give close attention to its performance. The farmer buys power-farming machinery to make money and he should try in every way to cut down the cost of operating it. Profits rise as operating expenses are lowered.

\section{HOW TO GET THE MOST OUT OF THE TRACTOR}

The tractor, in the first place, means a large investment. To the average farmer it is an expensive proposition, but much less so than the number of horses which are equivalent to it. He should aim to adapt it to as many different kinds of work as possible in order to make it pay for itself. A large number of the tractors in the field at the present time are used principally for plowing and threshing. They should be made to perform other kinds of work, such as hauling, harrowing, seeding, road building, harvesting, running ensilage cutters, saw mills, feed grinders, and many other farm jobs. All the drudgery of farm work can be performed by the engine.

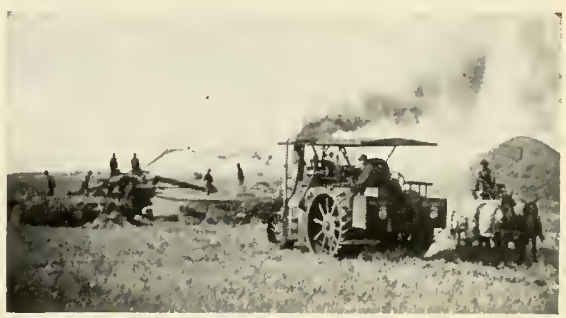

A RUMELY THRESHING OUTFIT (Fig. 4)

The idea of putting the tractor to work on different jobs is so that the fixed charges of interest and depreciation will be divided among a larger number of working days per year. Each engine has in it the ability to do a certain amount of work and it has been found that the greatest economy results in doing this work in the shortest possible space of time.

This can best be illustrated by an example in which we will assume that a farmer buys a tractor costing $\$ 2,000$, which, we will say, will have a life of I,, 00 working days. We will also assume that the annual repairs will be two per cent of the first cost and that the interest will be six per cent of the average investment or annual inventory value. If the life of the engine is distributed over a period of five years, it will be in service a total of 200

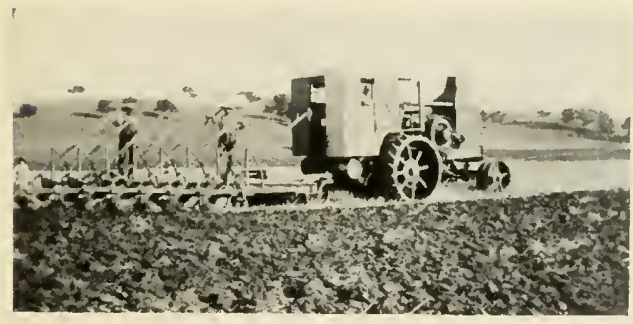

IN ALL WEATHER (Fig. 5)

This outfit is now a familiar sight on many - Corn Belt farms. working days each year, and the total charges for interest, depreciation and repairs will amount to $\$ 2.56$ per day. Now, if its life is extended over a period of ten years, it will be used on an average of 100 days per year at a cost of $\$ 3.12$ per day If it lasts 15 years it will work 66 days per year or at a cost of $\$ 4.40$ per day.

These costs assume that the annual repairs will be the same whether the life of the engine is five or fifteen years. This is not quite true, because the longer the life the greater will be the total depreciation when it is not working. The total repairs will consequently be greater. The interest is figured on the average inventory value. This is only fair because depreciation and repair charges are deducted each year. 
The farmer should not get the idea that he should save his engine simply to make it last longer, because as we have just pointed out, the longer the life the greater will be the cost per day.

The argument might be raised now that it would be better to buy a cheaper engine which will last only a comparatively short time. This is not true, however, because in figuring out the interest and depreciation charges it will be found that depreciation is five to six times as great as the interest. If a cheap engine is bought, the repair charges will also be greater than they would be in the case of a higher-priced engine.

\section{PREPARING FOR THE RUSH SEASON}

The farm orvner or manager should see to it that he has on hand sufficient supplies to carry him through the rush periods. In this connection if it is difficult to secure quickly supplies of fuel and oil, he should provide storage capacity large enough so that in a slack time he will be able to deliver a quantity to his farm which will last him throughout the season. By doing this much time will be saved when minutes are precious. It is also well to secure a supply of extra parts for the machinery which are apt to be

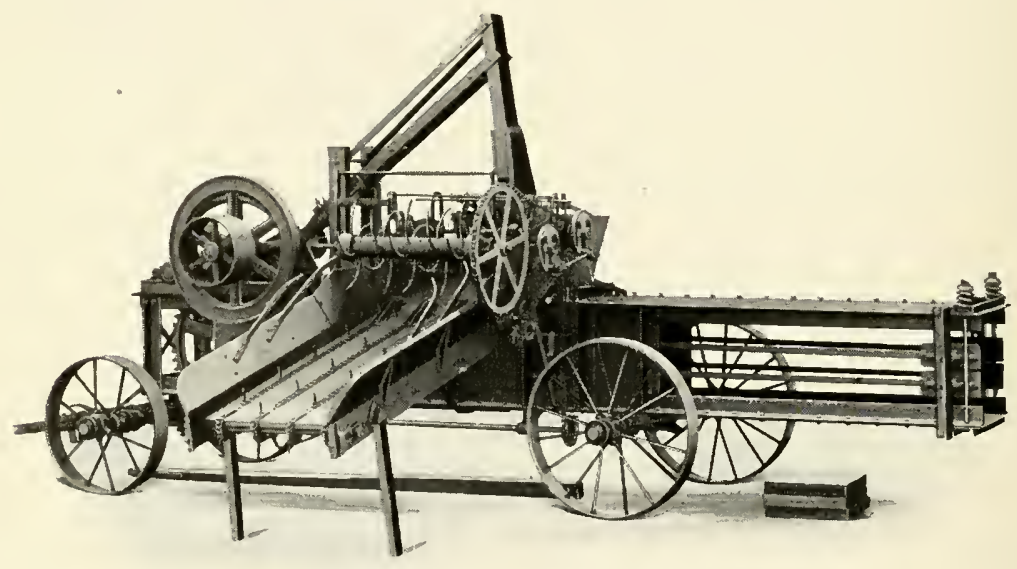

THE RUMELY AUTOMATIC BALER (Fig. 6)

A baler offers another opportunity for keeping the tractor busy on your own and your neighbors' farms a larger number of days during the year. It is a money maker. It will bale hay, straw, or cornstalks, thus perserving their feed value and saving barn space.

frequently needed. The time lost by not having a certain extra part is all too often more costly than the part itself.

During the rush of the season's work, if breakdowns occur, a great deal of time and money can be saved if repair parts are ordered by telegraph and shipped by express. The saving in crops will usually many times pay for this extra cost of securing these necessary parts.

An engine owner or operator should be very careful in ordering repairs to give as full information as possible. The number and description of the part should be given, the number of the machine and the date when it was purchased, if this information is available. This will enable the manufacturer to make immediate shipments and the delays in the field will be considerably shortened. 


\section{OVERHAULING THE EQUIPMENT}

A large amount of trouble and loss of time during the busy seasons has been due to neglect on the part of the farmer or his operator in not properly overhauling the equipment. This is very essential indeed. The best time to overhaul any piece of machinery is immediately after the season's work is finished. At that time the operator is more familiar with the extent to which the machine needs repairing and is able to do it at a much greater advantage than he would be at the beginning of the next season. He knows just where the trouble lies, and by giving it immediate attention the danger of neglecting any part will be largely done away with.

All the worn and broken parts should be repaired or replaced by new ones. In case of the tractor, the pistons should be cleaned and examined very carefully to see that there are no broken rings. The bearings should be

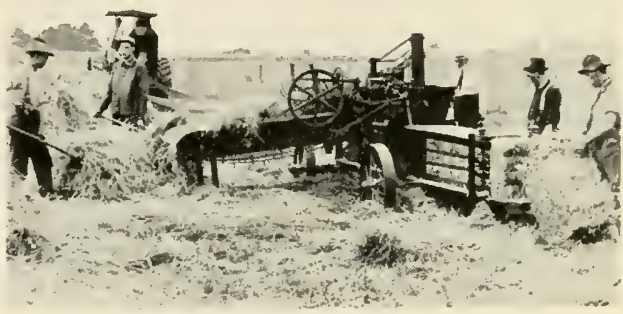

A RUMELY BALING OUTFIT (Fig. 7) carefully inspected to see that they are properly adjusted, and they should be re-babbitted if necessary. Inspection should be complete.

By properly and thoroughly overhauling each piece of machinery. a great amount of time and labor will be saved when the rush of the season's work is on. Nothing is more costly than a delay in the field to make repairs, when the fault might have been avoided before the work began.

It is sometimes necessary to completely overhaul a tractor two or three times during the year. This will depend upon the service which it receives, and the amount of attention that is given it while it is working. The owner of an outfit should insist upon having his men give the equipment the best possible care. He should keep watch to see that every machine is in perfect running condition.

\section{HOW TO AVOID DELAYS}

Accidents and delays should be avoided as much as possible. They can be overcome by having the men devote a certain amount of time each

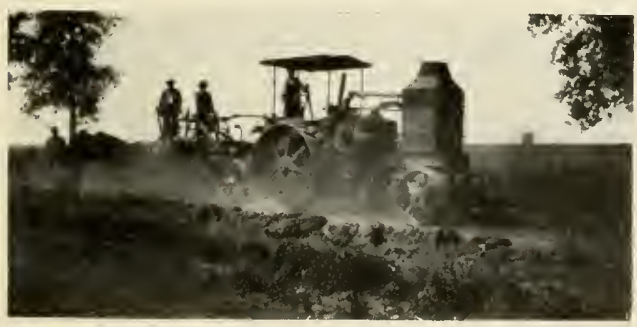

AN OILPULL TRACTOR HAULING AN ELEVATING GRADER (Fig. 8)

Keep the tractor busy during slack times on the farm by building and repairing roads. A good profit can be made at this kind of work. An engine will do it much cheaper than it can be done by horses.

When a tractor is at work in the field it should be kept in motion every possible moment. Lost time is expensive. Many farmers to save labor In the case of a tractor as well as other machinery, aside from filling the supply tanks, lubricators and grease cups, and making necessary adjustments, at least one hour should be spent each day in looking over the machine carefully to see that all nuts are tight and that there are no broken parts. The bearings should be examined at least once a week-some of them of tenerto see that they keep their proper adjustment. By being extremely careful in this way, the day to caring for the equipment. 
will let one man handle the outfit when in reality two are necessary. In plowing, for instance, where the automatic-lift plow and engine guide are not used, two men will do the work at considerably less cost than one can. But if this auxiliary apparatus is used one man can easily handle the work.

\section{DISTRIBUTION OF LABOR}

The labor should be so distributed that extra help will be available to get the outfit started early earh morning. An extra hand for such work as oiling, filling the fuel tanks etc., is a big help and money saved. During busy seasons the outfit should spend as many hours per day in the field as possible, and it is economical to have enough labor to keep it in operation. An extra crew should be hired to operate the outfit during the night, when the work must be rushed to the limit.

In the matter of labor, perhaps the best plan is to hire the men by the month, because in this way the owner will have the service of his crew during the season when there is very little work to do. The good manager will

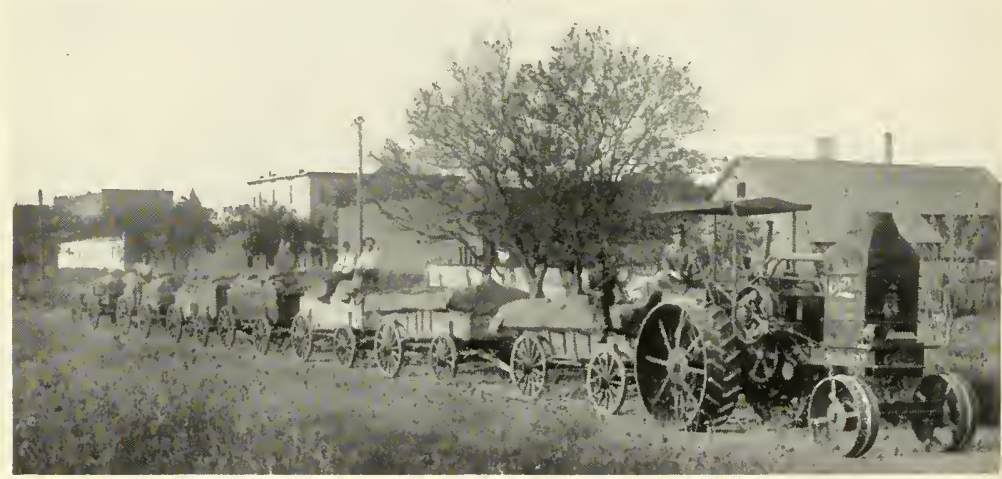

HAULING WITH AN OILPULL TRACTOR (Fig. 9)

This $15-30 \mathrm{~h}$. p. tractor is hauling 660 bushels of wheat at one load. It shows one of the many ways in which it is possible to keep an engine busy throughout the year

keep his men busy during slack times in overhauling the equipment and doing many odd jobs that are found on every farm.

It is advisable to pay a certain fixed rate of wages and allow a bonus for any extra work that is done. One farmer pays a flat rate per acre for the engine operator and helpers. A bonus above this is allowed for the whole number of acres plowed if the total each day exceeds a certain amount. This is an advantage to the workman because he not only gets his full wages for this extra work done, but he also receives a bonus added to this. It is best to make this bonus effective only when a man remains with the outfit until the close of the season.

The proper care of the entire equipment should not be sacrificed in order to accomplish a large volume of work. The farmer should seek to do as much work as he can with as little amount of wear and tear on the machinery as possible. It is not a good plan to allow hired crews to take long periods of rest then to crowd the outfit during the time when it is actually at work. This is a dangerous method of conducting any business and will invariably result in costly delays. While the outfit should be kept moving as much of the time as possible, still it should not be done at the expense of excessive injury to any part. 


\section{HOW TO PLACE THE RESPONSIBILITY}

If the owner himself is not working with the outfit he should make some one responsible for the proper care of the machinery and the amount and quality of the work done. If one man is given the responsibility for everything, he will see to it that the men under him do their part of the work, and the owner will find that he will get much better results than he will where no one in particular is accountable.

As in practically every line of work, cheap labor is by no means economical in connection with an engine outfit. The matter of wages should be a secondary consideration. The best to be had is money saved.

The duty of the man in charge should be to reduce as much as possible the time spent when the outfit is at a standstill. Anticipating accidents is a very profitable way of earning wages and only an experienced operator will be able to do this.

\section{DAILY RECORDS SHOULD BE KEPT}

The keeping of daily reports of cost and results should be required of the man in charge of the outfit. These should show the number of miles traveled or acres plowed; the total amount of fuel, lubricating oil and other materials used; repairs and time of making the same; time spent in inspecting and adjusting equipment, and any other charges and incidental expenses. Cash accounts should be kept so that repairs and overhead charges for the season's work may be divided as closely as possible and charged to the different jobs of work performed by the equipment and by the different machines in the equipment, if possible.

\section{INCREASING THE USEFULNESS OF THE TRACTOR}

The tractor is probably needed for plowing more than for any other work on the farm, due to the fact of the very large amount of power that is needed. Still on most farms its use is not profitable unless provision is made to keep it busy during as many months of the year as possible. It is not so long ago that it was thought that the farm tractor was practicable only for plowing and threshing, but now it is in demand for a greater variety of work than was imagined to be within its range of usefulness a few years ago.

The owner will find that he can also increase the usefulness of his engine by doing custom work, such as plowing, seeding, harvesting, threshing and other belt work. A good manager can always make money at this, and by establishing a reputation for doing good work, he won't have any trouble getting all the outside jobs he can handile.

Co-operative or community tractor outfits are rapidly increasing in number in various sections of the country and they are very popular. Progress in this direction is bound to continue. 


\section{Combining Field Operations}

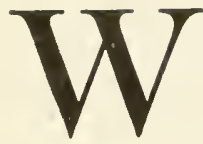

HEN horse power is used, only one machine can be hauled at a time because of the lack of power and the inefficiency of large teams. No manageable team can perform more than one job at a time, but with the tractor it is an entirely different proposition. Several machines can be coupled together and hauled behind it at one time. The advisability of hauling a series of implements is not to be doubted. It is a comparatively easy matter when the proper equipment is furnished for doing it.

Take seeding for instance: If a man is using horses, seeding is held up until after the plowing, discing and harrowing are completed, each being done in separate jobs. Also at harvest time, plowing can not be started until after the grain is cut. Where considerable time intervenes between each job a large amount of moisture is lost, due

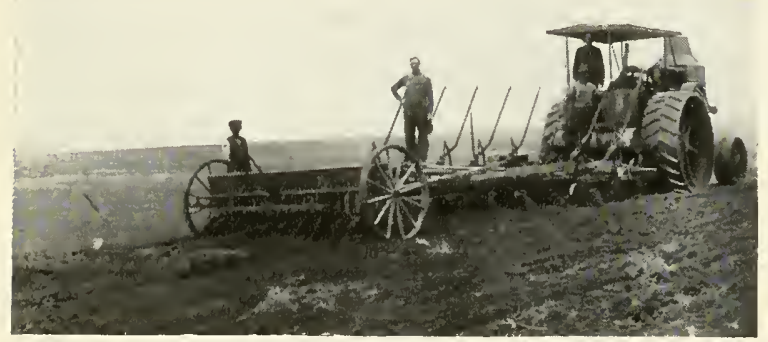

COMBINING OPERATIONS (Fig. 11)

This picture shows an OilPull Tractor hauling an eight. bottom Rumely gang, a drill and harrow at one time. Plowing and seeding at one operation saves time and moisture. The seed is imbedded in the moist earth freshly turned up by the plow. of moisture and time for growth. The usual excessive evaporation between operations is done away with.

\section{PLOWING AND SEEDING TOGETHER}

In certain sections of the country it is desirable to plow and seed at the same time in order to conserve the greatest possible amount of moisture. One farmer found that when he used his tractor merely for plowing and horses for hauling the drills, that the tracks of the engine could be seen in the growing grain throughout the season. The result was that he obtained about one-half a crop.

The reason for this was that by waiting to seed until the plowing had been finished, the soil had an opportunity to become dry and hard between the two operations, and the seed consequently did not have a chance to get the proper start. He remedied the trouble by hauling a harrow and drill directly behind the engine gang, thus plowing, harrowing and seeding at the same time. The harrow followed directly behind the plow and pulverized the furrow slices, making way for the drill. In this way, as soon as the ground was plowed, the seed was immediately imbedded into the moist mellow earth so that it got a good start before evaporation could have a chance to take place. By following this method all of the seed sprouted at the same time and the growth was uniform over the entire field. 
In most cases it would be desirable to use a disc harrow directly behind the plows and the drill behind the disc. Then with a packer and a smoothing harrow hauled behind the drill a first-class job of seeding could be accomplished.

\section{ONE TRIP INSTEAD OF MANY}

Preparing the seed bed with horses means separate trips back and forth across the field until the job is finished. It is hard work and as the soil becomes very mellow, their hoofs sink deeper and deeper and the task becomes very laborious. But by use of the method outlined above, the path of the tractor and other equipment is made but once over the field. There is no time intervening while one operation is being completed to make way for another. The furrows are turned, pulverized, seed is sown, and a dust mulch is formed to protect the moisture. Practically every ounce of moisture is conserved.

As minor items compared to soil moisture, the saving in time and labor are nevertheless very important. The work is done quickly and the usual slow process of seeding is accomplished in a comparatively short space of time. After covering the field once, the job is finished.

\section{RAPID WORK NECESSARY}

As soon as weather conditions permit the beginning of spring work, moments are precious. With the soil in the right condition it is essential that the grain be sown on time in order to get the maximum yields. The work must be done rapidly to avoid a loss of moisture. While it is more true in dry farming sections, it is nevertheless essential in humid regions as well. With horses the spring work must be started early and finished late. A week or two difference in the time of seeding very often changes what might have been a bumper crop to a complete failure. It is also a fact that grain which is cut early in harvest time contains a higher percentage of gluten and consequently a higher price on the market is received.

Where the work is done by animal power, a four-horse team is needed to haul one drill. Another team is needed to follow the drill with a packer and still another for harrowing. In all three teams and three men are required. They must plod back and forth across the field to do the same amount of work which can be accomplished by a small tractor hauling the drills, packers and harrows, and handled by two men.

More than that, the horses on an average will not work

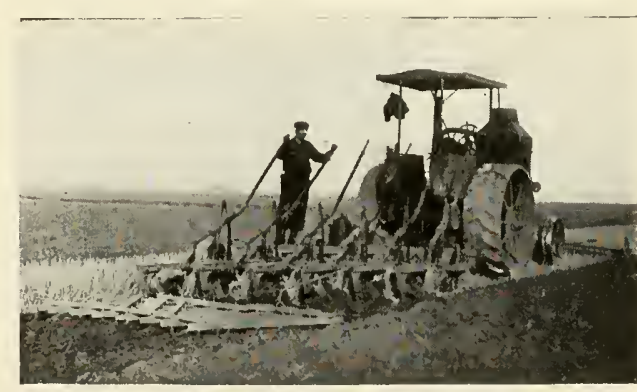

THE BIGGEST FARM JOB (Flg. 12)

This man with his OilPull Tractor, Dreadnought engine guide, Rumely plows and harrow is doing the hardest of all farm work with ease. The harrow behind the plows leaves the soil in nice condition. The engine guide enables him to give mosi of his attention to the plows. This is the ideal way of plowing.

more than eight hours per day but the tractor will work on an average of about twenty hours per day. A night and day crew furnished to operate a tractor outfit will do more than twice as much work as the equivalent number of horses in the same length of time. This is an advantage because the work can be done exactly when it should be. 


\section{IDEAL SEEDING}

Where seeding and plowing are combined, the object of the disc ahead of the drill is to wipe out the wheel tracks of the engine and pulverize the soil. Then the drill follows and drops the seed at a uniform depth. The packer behind this packs the earth around the seed and brings up the moisture by calpillary attraction, thus producing rapid sprouting of the seed. Finally with a smoothing harrow behind the packer, the surface is levelled off and a protective mulch is left. All these machines are hauled behind the engine at one time and only a few seconds instead of days or weeks elapse between each separate operation.

\section{THE RESULTS}

The beneficial results to be gained by combining operations are:

I. To save time.

2. To reduce to a minimum the time between each operation in order to confine the work to a period when the conditions of the soil and climate are most favorable and to avoid a negative action of the soil between each job.

3. To cut down the number of trips on the plowed ground.

4. To load the tractor to its normal, full-load capacity by a combination of the various machines.

With horses the farmer is unable to concentrate their power to such an extent as to combine the different operations, but with an engine it is comparatively easy to combine a number of the various tasks so that they can take place at one and the same time.

\section{Getting a Tractor out of the Mud}

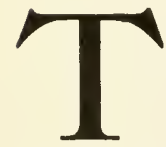

HE first thing to do when an engine gets into a mud or bog hole is to unhitch from the load you are hauling. Some soft spots are small and only a short distance across. If you get into one and find that your engine will not be able to pull out with the load, stop immediately and unhitch from the plows or machines you are pulling. Drive the tractor across to firm ground where it will be able to get a good grip on the soil. Then by means of chains or cables pull the outfit across.

If the engine can not pull itself out with its own power, do not attempt it by backing up and going forward to work yourself out, as the tendency will be for the drivers to make a bigger hole in which to settle. Wait until you have provided planks, posts, sticks of wood, or stones so that the drivers will he able to get a footing. In trying to get out keep the mud scraped out from between the lugs on the drivers to enable them to take hold.

In many cases it will be found that the ground is so soft that the wood or stones will be forced into the ground, and will offer practically no means for the wheels to get a footing. They will also become covered with mud and get so slippery that they will offer no resistance whatever.

The best method to use in a case of this kind is to wrap a chain securely around one end of a plank and the other end of the chain around the rim of the drive wheel. Do this to both drivers, if necessary. Then by starting the engine it will pull itself up on to the planks. Then unfasten the chain from the drivers, and if the planks are long enough, you will be able to run out of the hole on them. If they are too short for this, lay some more in front of them lapping them about a foot. 
Another method which can be used in extreme cases is to bury a "dead man" some distance ahead of the engine. One end of a cable should be attached to this "dead man." Then fasten the other end to the rim of the driver and start the engine. The cable will be wound about the wheel as on a drum, and the tractor will pull itself out.

If the engine is down so deep that the gears, Hywheel or the frame rests on the ground, it will first be necessary to jack it up far enough so that planks or posts can be shoved under the wheels to take the weight and to clear the other parts. Do not try to move an engine by its own power or otherwise when any part except the wheels rests on the ground.

Before attempting any method, the first thing to do is to take the mud away from in front of all four wheels. The reason for this is that considerable power is needed to get over the obstruction, and the harder it is for the tractor the more difficulty there will be in getting out.

It is best to dig a trench in front of all four wheels, if necessary, and a little wider than the width of the wheels. Dig to the bottom of the wheels and let the trench gradually slope up to the surface. It is much easier for the engine to climb this incline than a steep one, as would be the case were no digging done.

\section{Plowing}

$\mathbf{P}$

LOWING is the most important operation on the farm. It is also the most difficult - in fact, the heaviest of all human tasks. More power is necessary for this purpose than is consumed in all the factories of the world.

Plowing has been designated the "peak load" in agriculture, since it requires more power in a given length of time than any other farm task. To produce the wheat crop, 60 per cent of all the power required is used up in the shallow plowing that is most generally practiced. Deep plowing, then, demands a much greater expenditure of energy.

Because of the large amount of power needed, plowing is consequently the most expensive job on the farm. It is the biggest item in the cost of producing crops.

\section{HOW THE TRACTOR CUTS THE COST OF PLOWING}

The coming of the farm tractor has revolutionized plowing, as it has all other farm work. It has cut ten cents per bushel from the cost of raising

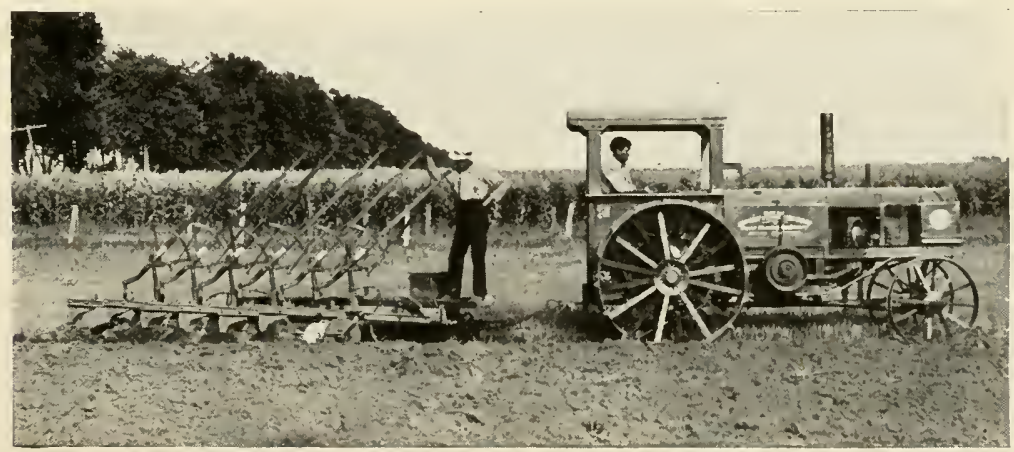

THE PLOWING OUTFIT FOR THE SMALL FARM (Fig. 13)

A Rumely GasPull Tractor and a six-bottom Rumely engine gang that is doing the work of three to five men and fifteen horses. This is an ideal rutfit for the average Corn Belt farm. The tractor is well adapted to general-purpose farm work. 
wheat. This is due very largely to the saving it has effected in the operation of plowing.

In the first place, one man with a 15 h. p. modern traction plowing outfit can plow as many acres per day as four to six men with teams. Or with a 30 h. p. outfit he will do the work of ten to twelve men with teams. The tractor increases the ability of the individual worker to accomplish more work, because it placed in his hands the control of more power. It is a laborsaving proposition.

Engine plowing can be made of much better quality than horse plowing. A more even job can be done, as the furrows are the same width over the entire field. Deep plowing can also be practiced. While it is possible to plow deep with horses, it is not profitable. But with a tractor we can turn as deep a furrow as we like and just as economical as a shallower one.

Power capacity is at a premium on most farms at certain times of the year. Especially is this true in the case of spring plowing. Here is where the tractor has the advantage over the horse. It can be made to do double duty by using it both day and night. In this way it will do as much work as twice the number of horses that equal its normal power capacity. The farmer is able to plow when the best weather and soil conditions prevail and to fit his ground in ample time for seeding and other crops. It is a time saver.

\section{HORSE POWER EXPENSIVE}

If a farmer maintains a sufficient number of horses the year round to properly meet the "peak load" of the plowing season, a large percentage of them will be idle the greater part of the year. The average farmer finds that he can profitably keep so many head of horses the year round. But when it comes to plowing, he can always use a much larger number to mighty good advantage.

The fact is that the number of horses that can be economically kept on the farm is limited because of the high maintenance cost. They differ from the tractor in that they must

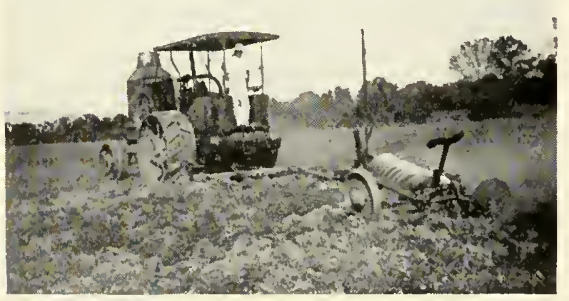

A HARD PROPOSITION (Flg. 14)

This OilPull Tractor and Sanders disc plow are breaking up soil that is so hard that a moldboard plow couldn't penetrate it. be fed and cared for 365 days of the year and on the average each horse works three hours per day throughout the year. The tractor, on the other hand, costs nothing when idle. A!l expenses stop with the wheels. And when working the cost of fuel and lubricants is less than feed for the number of horses that equal it in power. When properly cared for, the repair bills will be less than shoeing and veterinary bills for the horses.

The tractor can be properly housed in a building one-tenth the size and cost of a barn for the number of horses that equal it in power.

Taken all in all, the tractor has far greater advantages as a source of farm power than does its rival the horse. It also relieves the horse of endless farm drudgery, particularly is this true in the operation of plowing.

Don't condemn the tractor. If you can not get it to do what the company claims for it, find out first whether the fault is your own or the manufacturer's. Engine owners are too free with their condemnation of a machine when in a great many cases the trouble was due to their own ignorance or mismanagement. Know your tractor as you know your horse, if you wish to make a success with it. 


\section{Power-Plowing Equipment}

A

REMARKABLE improvement in traction plowing outfits has been made in the last two years. The efficiency of the up-todate outfit is very high, compared to some of the earlier attempts. The big advantages of engine plowing are coming to be more and more widely recognized, and it is winning favor wherever it has been given a fair trial.

The two prime essentials in a tractor plowing outfit are, of course, the engine and the gang plow.

\section{THE TRACTOR}

It may be either a steam or internal-combustion engine, but for general

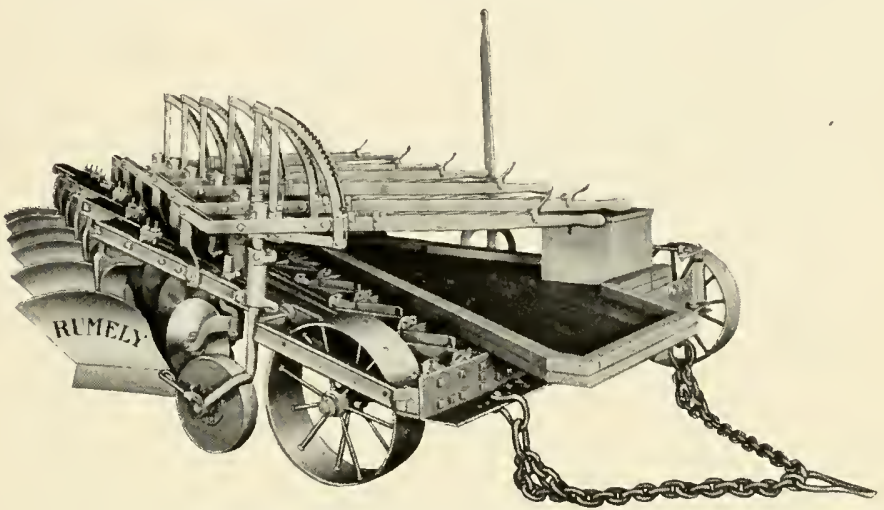

THE RUMELY ENGINE GANG PLOW (Fig. 15)

Select an engine gang that is easy to handle and light of draft. This plow together with a Rumely OilPull Tractor makes a first-class combination for plowing.

farm work the latter is preferred and has many advantages over the former. It is the ideal farm motor.

There was a time when the gas tractor was very much in disfavor because of its unreliability. That time has passed and we find on the market at the present time engines which are very reliable and which give highly satisfactory service when properly handled.

The prospective buyer will find tractors of one, two and four cylinders, vertical and horizontal, high and low speed, and large and small. His choice should be selected with much care. He should study the conditions under which the engine must give service. He should take into consideration the amount of work to be done and the power needed to do it. Selection of the power unit should be made only after a careful investigation of all factors.

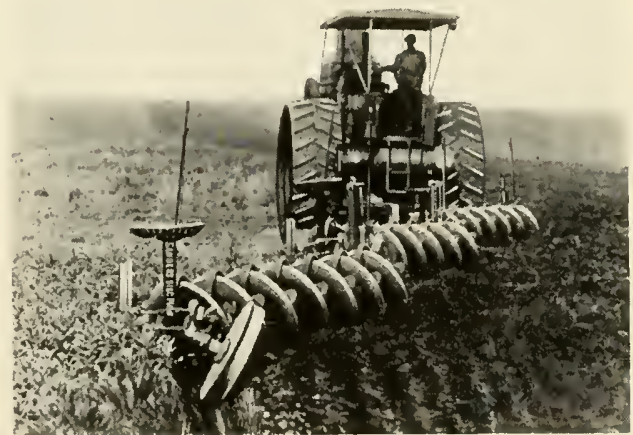

THE USEFUL DISC PLOW (Fig. 16)

For hard, tough ground, or wet soil where moldboards will not scour, the disc plow is indispensable. This picture shows a Rumely OilPull Tractor and three-section Sanders disc gang. 
As to the capacity of the different tractors, it may be said that in general an engine rated at I5-tractive, 3o-brake $h$. p. will haul about four 14 -inch plows in breaking virgin sod and five to six plows in stubble or tame sod. This is at the rate of one and three-fourths to two miles per hour.

A 30-tractive, 6o-brake h. p. tractor will haul eight to nine bottoms in breaking and ten to twelve bottoms in stubble or old land.

\section{THE ENGINE GANG PLOW}

The engine gang is of two different types - the disc and the moldboard,

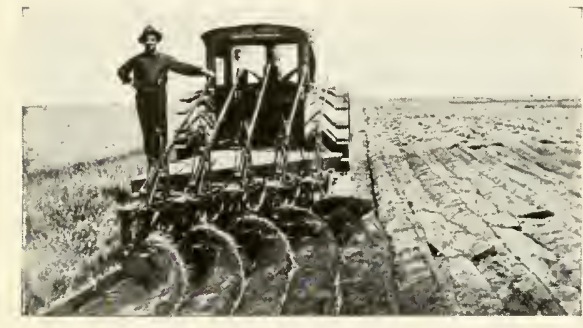

A ONE MAN OUTFIT (Fig. 17)

A Rumely GasPull Tractor turning sod in the open prairie. One man does the work plowing from 10 to 12 acres in a day of 10 hours.

Each has its advantages and disadvantages. The selection should depend upon the kinds and conditions of soils in which they must render service.

The disc plow is essentially a pulverizer. Its natural field of usefulness is in the South, the Southwest and on the semi-arid plains. It has the advantage in that it will penetrate ground that is too hard and dry for a moldboard plow. It is also somewhat lighter in draft than the latter type.

The moldboard plow is in most universal use, and where either one can be used it is to be preferred, as it gives in general much better results.

\section{PLOW BOTTOMS}

Bottoms which cut a furrow $\mathrm{I}_{4}$ inches wide are in most general use.

There are three general classes of plow bottoms, depending upon the shape of the moldboard-stubble, general-purpose and breaker bottoms. Variations of these are the slat and rod breaker bottoms.

The moldboard of the stubble bottom is steep with an abrupt turn where the furrow slice leaves it. It has a tendency to break down the soil with a considerable pulverizing action, when the furrow is turned. It is especially adapted for plowing stubble ground, where the crop is to be put in at once, and in soils where a finer and closer texture is desired.

The general-purpose bottom is more sloping and with a less abrupt curve than the stubble type. It leaves the furrow more on edge. The pulverizing action is much less, the furrow slice being broken up into large pieces. which are more or less exposed to the action of the weather. This bottom is adapted to soils of the

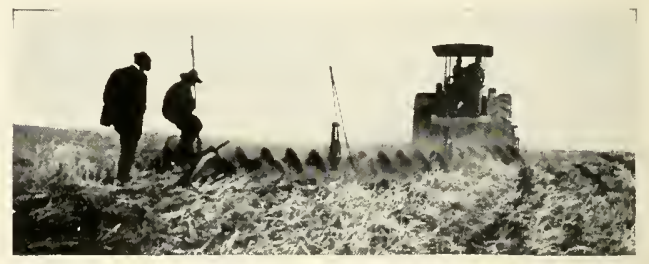

Fig. 18)

There are sections of the country where the disc plow is indispensable. This picture shows an OilPull Tractor hauling a three-section Sanders disc plow. clayey type, where it is desired to make them more porous. It is often used for fall plowing on stubble ground or light sod.

The breaker bottom has a long sloping moldhoard with a gradual curve. which completely inverts the furrow slice with practically no pulverizing action. It is used for plowing virgin prairie sod, or where there is considerable green manure or trash to turn under.

The slat bottom is used in gumbo and the other heavy soils, where other moldboards will not scour readily. The rod breaker is also used where the ordinary breaker will not scour. 
The selection of the proper type of moldboard will depend altogether on the kind and condition of soils in which the plow is to be used. It is next to impossible to lay down any hard and fast rule as to this. It is simply a matter of choice in which the farmer will be best governed by his own experience or that of his neighbors and the manufacturer's recommendation.

\section{EXTRA PLOW PARTS}

When purchasing an engine gang, it is very essential that a farmer should supply himself with an extra set of shares. During the busy plowing season, the shares can then be changed quickly, and no time lost in the field while the set is being sharpened. A sharp set is always ready for immediate use. Farmers know how valuable this saving in time is. Money invested in thisextra set is money well spent.

It is also a wise plan to have a few extra plow bolts, spring washers, break pins and grease cups in the tool box, as there are many

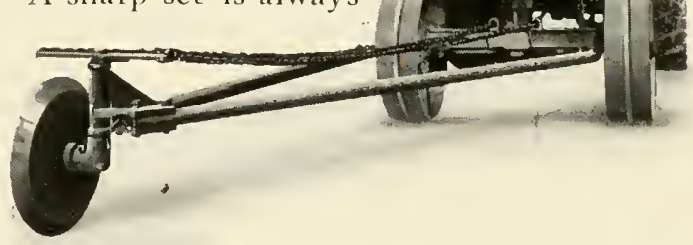

THE DREADNOUGHT STEERING GUIDE (Fig. 19)

It provides a very reliable and automatic method of controlling the direction of the tractor in plowing. It allows the operator to give his entire attention to the engine and plows.

times when things of this sort are very much needed. They are very often the means of saving a great deal of time, especially when every minute means money saved or lost.

\section{THE ENGINE GUIDE OR SELF-STEERING DEVICE}

Aside from the engine and plow, the next most essential part of the equipment is the engine guide or self-steering device. No farmer can afford to be without one. Formerly two men were required with an outfit for highest efficiency. One man could do the work, but to have two the extra wages were much more than made up by the increased acreage which they could plow.

But with the engine guide only one man is needed while at work in the field. It is always well, however, to have extra help for such work as oiling and adjusting the equipment

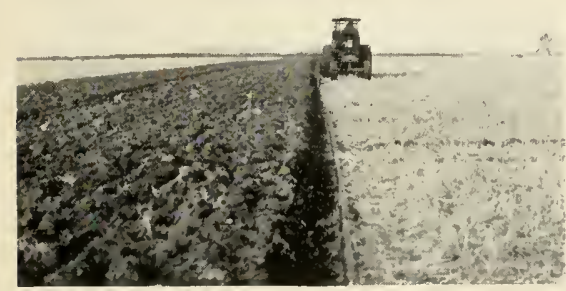

THE DREADNOUGHT IN ACTION (Fig. 20)

There is no excuse for not having a straight furrow, when an engine guide is used. Can you beat this job with horses? before work in the field is started each day, and for changing plow shares, running errands and many other odd jobs.

The operator starts the outfit at the beginning of the furrow. He does not have to touch the steering wheel until the other end is reached, because the guide travels along hugging the furrow wall and keeps the outfit at the same distance from the plowed ground at all times. The operator is at liberty to watch his plows as much as he likes. since the self-steering device is automatically guiding the engine. It gives him an opportunity to get off and make adjustments on his plows, if necessary, while in motion. He is free to give more attention to the outfit in general, and see that every part is working properly.

He is doing a large volume of work and is having an easy job of it. He is also doing a better job, as the furrows over the entire field are cut exactly the same width-a field of smooth, even plowing is the result. 


\section{The Automatic Plow}

$7 \mathrm{ren}$

HE automatic-lift plow is the latest step in the development of power-plowing machinery. In Figure $2 \mathrm{I}$ is shown a plowing outfit, which is very nearly automatic in its operation. It consists of fit, which is very nearly automatic in its operation. It consists of
an engine guide, engine and an automatic-lift plow. When plow-
from one furrow's end to the other, the operator has only to sit with folded arms on his seat on the tractor and watch his outfit.

At the end of the furrow, simply by pulling a string, the plows are lifted automatically by a mechanism attached to the front beam of the gang. On starting into the furrow again, another pull of the string causes the plows to drop into the ground.

This arrangement absolutely does away with an extra man on the plows. It not only saves labor, but time also. It is not necessary for the engine to slow down when raising or lowering the plows in turning, as is true of hand operated plows. The saving of labor in connection with the operation of a plowing outfit is an item well worth consideration.

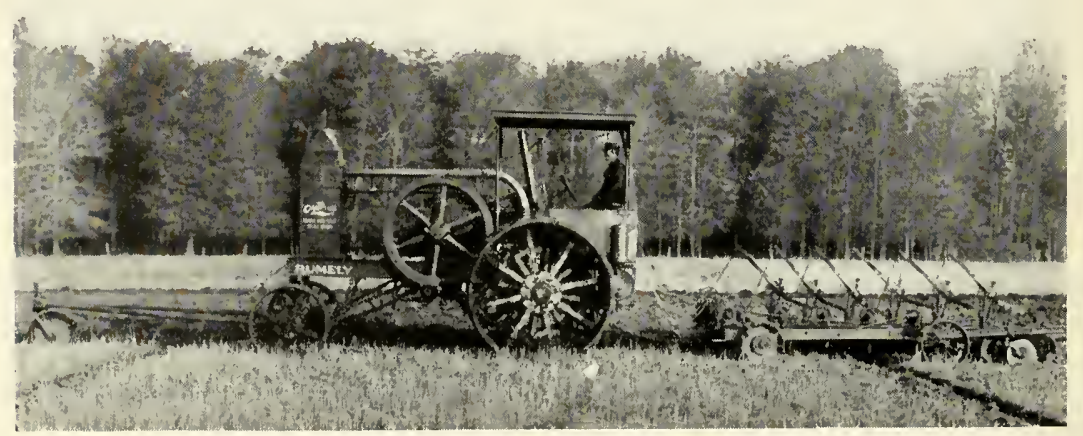

AN AUTOMATIC PLOWING OUTFIT (Fig. 21)

Equipped with a steering guide, a kerosene tractor and an automatic-lift plow, plowing is made an easy job for this man. With such an outfit he can easily plow an acre every hour.

The tendency among tractor owners is to let one man handle the plowing outfit. In most cases this is done, no doubt, because of the lack of labor. I have operated an engine and plows alone that were not equipped with steering guide or automatic lift. I found it was not only all one man wanted to do, but that the wages of an extra man could be more than saved in the larger acreage plowed each day. An extra man to look after the plows also made possible a much higher quality of plowing.

The addition of the steering guide and the automatic lift make an ideal plowing outfit. They enable one man to do a job of plowing easier and better than two men could without this auxiliary equipment. A man handling such an outfit has a good opportunity to keep a lookout ahead and is in a much better position to control the raising and lowering of the plows than a man operating a hand-lift gang. With a complete outfit, as shown in Figure $2 \mathrm{I}$ it is a comparatively simple matter to finish up the lands.

The latest improvement in the automatic-lift plow is the individual lift. With this the operator can raise or lower any one bottom or any number of bottoms at a time or all at once. In other words, it is possible to operate any plow independently of the others. This feature is a decided advantage in a great many cases. 


\section{Adjustment and Alignment of Plows}

$\mathrm{O}$

NE of the most important factors in the successful operation of the engine gang is the proper adjustment of the plows. In order that the plow will enter the ground at the proper depth, in most makes of plows the point of the share or lay should dip down a slight amount. This is known as the "suction" of the plow. For engine plows it varies from three-sixteenths to one-half of an inch. Suction should be given so that it will not affect the general shape of the share. In one make of plow the angle of suction begins three inches from the point of the share. This will vary in different makes.

The plow with the proper suction will give more uniformity to the bottom of the furrow and a more steady pull. It permits the point of the share to wear down and still leave a straight bottom. It also provides for the penetration necessary in an engine gang and the plow will work without an excessive amount of draft on the engine.

To make a plow bottom take a full width furrow, most plowshares are given what is called "land." It is the amount which the point of the share turns toward the left from the line of the landside. The point of the share in one make of plow is set one-sixteenth of an inch to the land, but in addition to this the beam is set so that the total land suction is one-fourth of an inch. This protects the landside and creates a desirable draft.

\section{TESTING THE ADJUSTMENTS}

A good way to tell whether or not the share is properly shaped is to set it on a smooth surface, such as a floor or the table, just as it would set in the bottom of a furrow. The entire cutting edge should touch the surface. The shares of an engine gang need no bearing at the heel or wing, as the weight of the "suction" is carried by the gauge wheel. With a share in the right position there will be a clearance between the floor and the heel of its landside of about one-sixteenth of an inch. This shows that it has the proper amount of "suction." In this position it can also be determined if the share has the required amount of "land."

Some plows are given no land or bottom suction whatever. This is taken care of by means of the beam adjustment, the proper suction being given by raising or lowering the front end of the beam or moving it to one side or the other. Some manufacturers provide for suction by means of an adjustable standard break pin.

If the share does not make a smooth, even joint with the moldboard, shims should be placed under the share or moldboard. If this is not done the soil will stick there and may interfere with the scouring of the plow.

The alignment of an engine gang plow is controlled by certain adjustments. usually at the point where the beams are attached to the frame. This adjustment varies widely with the different makes of gangs. Each manufacturer gives complete instructions for making any changes of this nature on his product. The line of draft should be as near parallel to the length of furrow as possible. A little deviation toward the land would not be harmful, but never toward the furrow. The height of hitch is fairly constant in all makes.

\section{SHARPENING AND HARDENING PLOWSHARES}

Whether the farmer sharpens his own shares or has his blacksmith do it for him, he should see to it that they conform as nearly as possible to the measurements of the plow when first purchased. 
The method of sharpening and hardening depends on the type of share. Shares that have been hardened at the factory should be hardened whenever they are sharpened. Soft center shares such as are used on breaker bottoms should not be hardened but heated only to such a point as is necessary to hammer them.

When sharpening, no more than six inches of the edge should be heated at a time so as not to distort and crack it. By heating only a little of the edge the temper will not be drawn.

In sharpening a hard share the above should also be observed. But after sharpening the point should be heated to a high red heat and then plunged into water to harden it. There is no danger of too suddenly cooling the point on a hard share.

\section{PROPER ADJUSTMENT OF ROLLING COULTERS}

This is very essential in getting best results from a plow. A change in the adjustment will bring about a change in the quality of plowing and the amount of drawbar pull required. In plowing stubble the coulter should be set to cut about one-half the depth of the furrow and should be set about three-fourths of an inch outside of the line of the landside.

In plowing tame sod or in breaking the coulter should be set deeper. In very tough sod it should cut the full depth of the furrow.

Also in plowing stony or stumpy land, it should be set to the full depth of furrow in order to protect the point of the share. Some authorities advise that it should be set a trifle deeper than the point of the share.

Under ordinary conditions it may be taken as a rule that the center of the coulter should be directly above the point of the share. An exception to this, however, is in plowing hard, dry soil. In this case the coulter should be set a little farther back. This lets the point into the ground first, which draws the coulter down. If set in the ordinary way, or especially if set too far forward, the coulter would not be able to penetrate the hard ground and would hold the plows out.

The coulter should also be set a little back in plowing wet corn-stalks. It should likewise be set close to the shin of the plow. Then the point will penetrate first and draw the coulter down cutting the stalks in two.

Sometimes when a plow will not scour, the fault may be remedied by a slight adjustment of the coulter. Try placing it a little more to land and a trifle forward. This will place more friction upon the point of the share and will often assist in starting the plow to scour properly.

Ten years ago the horse plodded along undisturbed ahead of the plow. On!y the daring prophet could see in cases here and there of successful traction plowing a hint of the great progress of the decade in the substitution of mechanical for animal power. The success of the automobile had not suggested the feasibility of supplanting the farm horse in the field by a motor, and the present high prices of horse feed had not caused the farmer to cast about for a cheaper source of power. The swift and successful introduction of the farm tractor is a matter of almost current history. Five years - ten at the outside - mark the step from the single purpose threshing engine to the all round tractor now used to plow, to harrow, to drill, disc and harvest, to haul and to thresh, and do all of the farmer's heaviest work. The farm tractor is here and to stay. With its invasion of an ancient field have come a host of new problems and the necessity for the readjustment of some of the present ideas of farm economics.

-L. W. ELLIS. 


\section{Hitching the Plows to the Engine}

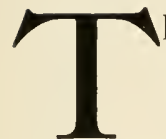

HE main idea to keep in mind in doing this is to hitch the plows to the engine in such a way that the best possible work will be done with the least possible draft and expense. The proper working of both engines and plows will depend very largely on the method used. While it is absolutely impossible to eliminate the sidedraft in the plows, it should be kept at a minimum, as an undue amount causes excessive wear and tear on the whole equipment. As the engine is the most expensive part of all it should, consequently, receive the most care and attention, and this matter of hitching different machines to it should be thoroughly studied out, as the life of the engine is materially affected by it. Also the hitch will in no small degree affect the quality of the job, which is more important than all the machines.

Figure 22 shows a top view of an engine plowing outfit and the method of attaching the plows to the engine. The operator should be very careful to hitch them as near the center of the engine as possible in order that the center of pull may come as near in line with the line of draft as it can be made to. At the same time the engine should travel as close to the furrow as it can without crushing the landside. The proper distance has been found to be from six to twelve inches.

The two draft chains between the engine and plow should be of the same length, as chains of uneven length will bring about more or less of a strain or twisting effect upon the plows.

If the gang plow is hitched as shown in Figure 22 and the first plow at the right hand side is cutting too wide a furrow the chain clevis should not be shifted from the center hole of the engine drawbar, but the other ends of the chain should be moved over into the holes that are farthest to the left on the frame of the gang.

If the furrow is still being cut too wide the only remedy is one of two evils. Either set the clevis a little to the right on the engine drawbar or shorten the left chain until the proper width furrow is cut. The latter is without a doubt the lesser of the two evils, hecause, as it was pointed out before, the engine should receive the best care as it is the most expensive part of the equipment.

Another method of hitching the plows to the engine that is frequently used is by means of the cross-chain hitch. The plow chains are crossed and hitched to the drawbar. The chief advantage of this is found when turning at the end of the land. The plows will travel straight ahead for some distance after the engine has started to turn. This is due to the equalization of the cross chains.

The disadvantage of this method is that it is next to impossible to apply the load to the center of draft of the engine, which causes the gears to wear on one side more than they do on the other. It is harder on the engine than the hitch shown in Figure 22. It is also much more inconvenient in hitching to or unhitching from the plows.

\section{HITCHING DISC PLOWS}

The hitch in Figure 22 can also be used when hauling several sections of disc plows instead of moldboards. A wooden evener takes the place of the front beam, and several sections are hitched to this evener by cables of different lengths. Figure 24 shows a method of hitching a gang of disc plows to the engine. The front end of each section is hitched to the rear end of the section ahead of it by means of chains furnished with the plow. 


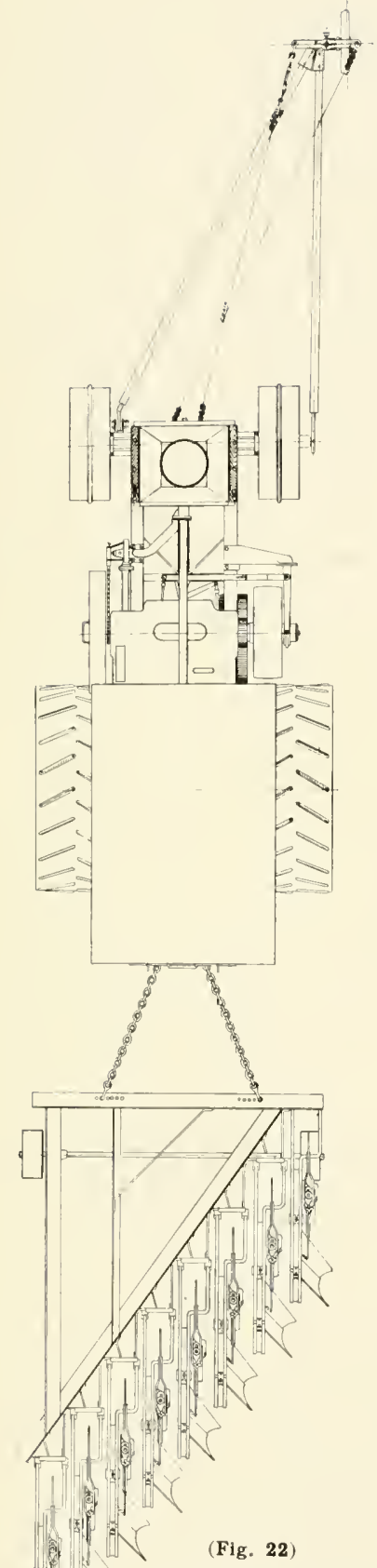

Plan view of trac. tor, engine guide and gang plow. Proper hitch for plowing. (Note
holes in front frame of holes in front frame of be made to travel closer or farther away from the furrow.)

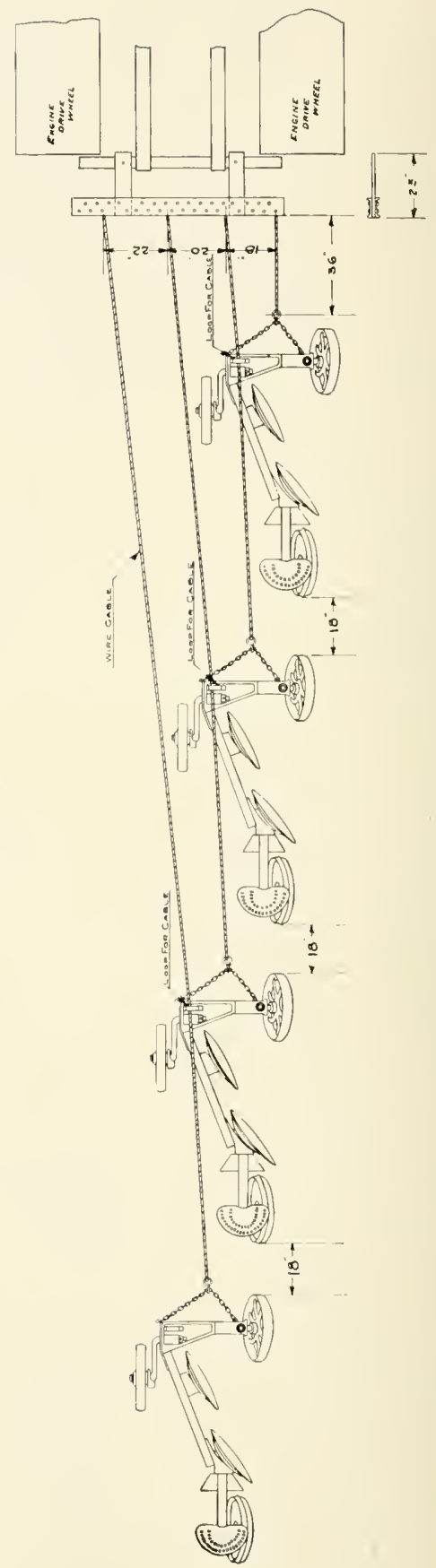

(Flg. 23)

Method of hitching Spalding deep tilling machines to an OilPull Tractor (Note auxiliary drawbar.) 
With a two-section disc gang two cables are used as shown in the illustration. If more than two sections are hauled, it is sometimes found unnecessary, under certain conditions, to connect the rear of the last section to the evener, but in many cases it will be found advisable to do so. The farmer should use his own best judgment in this.

\section{HITCHING DEEP TILLING MACHINES}

The increased use of deep tilling machines in many sections of the country has more than ever taught the farmers the value of the farm tractor

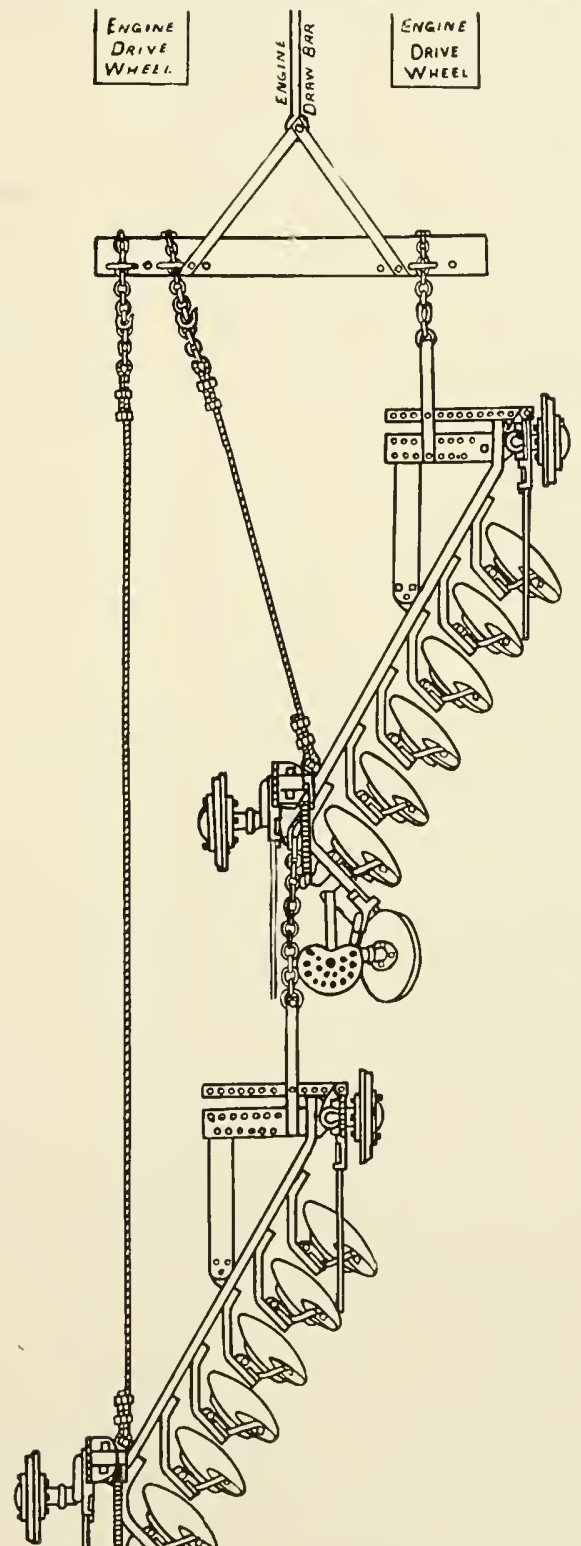


for larger power capacity. Plowing and pulverizing the soil to a depth of twelve to sixteen inches means power and much of it. Horses are at a decided disadvantage because of their lack of endurance for so difficult a task and the inefficiency of large teams.

Many farmers have solved the problem of deep plowing by hitching a number of deep tilling machines behind their tractor. Figure 23 shows a method which has given very satisfactory results. Each machine is attached to the engine drawbar by means of wire cables. Each cable (see Figure 23) is passed through a loop on the machine ahead. This loop is bolted to the frame and its edges should be rounded off smooth so as not to cut the cable. The object of using the loop is to hold each machine in its proper place behind the one in front of it.

Each machine requires about eight feet of space. A $5 / 8$-inch steel cable is used with a steel loop on one end and a heavy grab hook on the other to connect to the engine drawhar and chain on the plows. As each plow will vary more or less in the amount of side draft, the cables should not be cut to any exact length but should be gradually shortened so that the plows will have eighteen to twenty-four inches between them.

In using Spalding deep-tilling machines behind tractors it is necessary that they be weighted heavily if the ground is very hard or dry. For breaking the heavy adobe soil in Colorado it was necessary to carry 400 pounds of dead weight on the plows.

It requires a considerable amount of experimenting to get several plows to trail back of the tractor. It is atways advisable to turn the tractor to the right when plowing, as the engine can be kept on good, solid footing, and if the plows crowd they will be in the plowed ground where they will not jump out of the furrow.

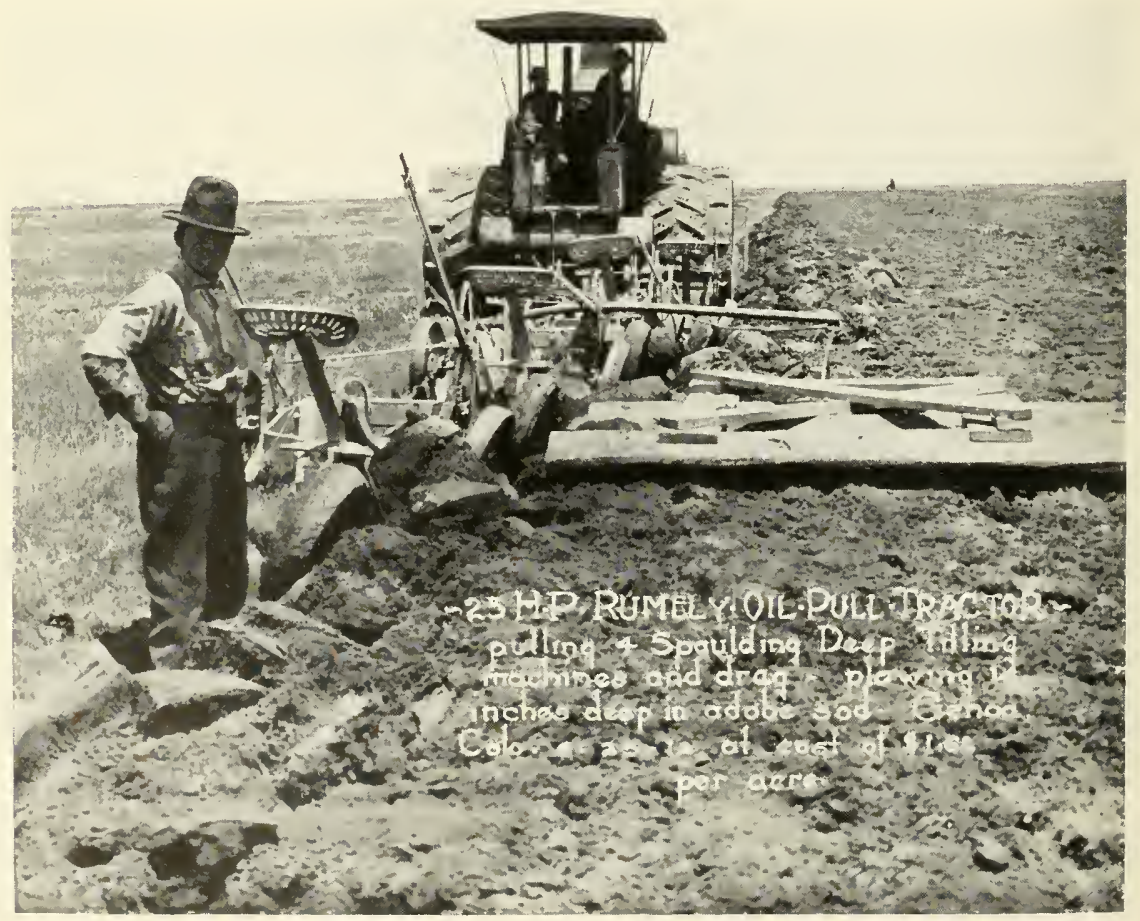




\section{Laying Out the Field for Plowing}

$\mathbf{S}$

UCCESSFUL plowing with tractor outfits depends very largely on the method followed in laying out the field and the manner of plowing it. The best and the easiest way in the greater majority of cases is to follow the method as shown by Figures 26 and 27.

Whether the field is square, rectangular or irregular in shape, large or small, the first thing to do is to set guide stakes at each corner, of equal distance from the adjacent sides of the field, about eighteen to twenty paces (fifty to sixty feet). This should be measured as accurately as possible, as it makes it more convenient when finishing up the field.

Then with the single right hand plow of the engine gang set to cut a shallow furrow, plow in as straight a line as possible between each stake and around the entire field. The strip outside this furrow provides ample space in which to turn the outfit at the ends of the lands. The plowman should pull out the plows and drop them in on this furrow which serves as a mark. By doing this a more even job can be accomplished.

\section{THE METHOD OF PLOWING}

The part outside of this guide furrow should be left till last, after the portion inside has been plowed off in lands.

That part of the field inside the mark should be plowed in convenient lands by a combination of backfurrowing and dead furrowing. The lands should not be too wide, as considerable time will be lost in traveling around the ends.

The best method is to divide this portion up into a series of lands of ten

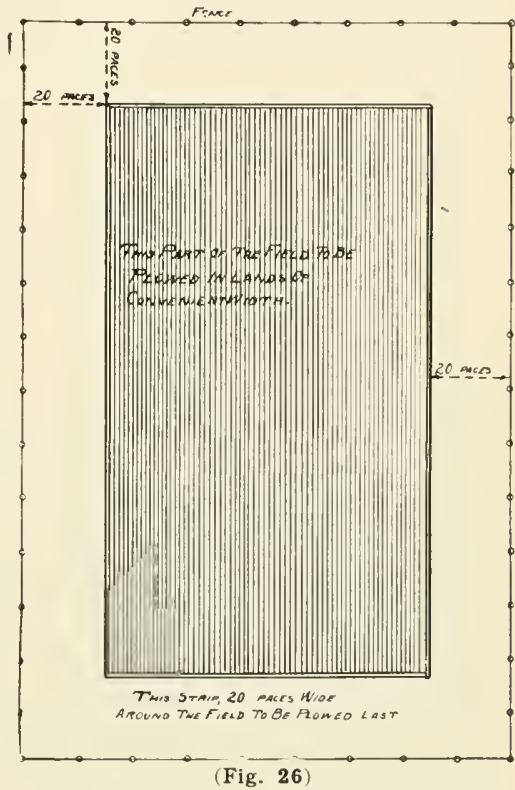

How to lay out and plow a field with a tractor. This is the easiest and most practical method which can be used.

to twelve rounds each by setting guide stakes. The operator should be careful to drive straight furrows in striking off these lands so he will come out even when finishing.

After the lands have been plowed off, the strip at the outside is plowed by starting in next to the plowed land at the corner, where it is desired to finish up, and plowing around and around the field. It should be so planned that on the last round, if in a fenced field, the gang will be taking its full width. In this way the operator will be able to plow closer to the fence.

\section{PLOWING THE HEADLANDS}

In plowing the outside strip, it is best to follow the plan shown in Figure 27. Start at one corner by dropping in the plows nearest the plowed land in such a way that the furrow ends will be on a diagonal. In coming out at a corner do the same thing, only start by raising the plows farthest away from the plowed land. The turn can be made by making a circle at the corners. This shoukl be done on the first one or two rounds. 
After this the operator can make an easy gradual turn and no land will be left unplowed or plowed twice.

By properly following the method as outlined above, the engine will at no time travel on the plowed ground. When the last round at the outer edge is plowed, the field is finished. And if the proper care has been exercised in doing the work, the result will be a smooth, even job, which cannot be equalled by horse plowing or any other method.

\section{OTHER METHODS OF PLOWING}

There are two other methods which are frequently used for plowing a field. The first is to begin at the outside and work toward the center by

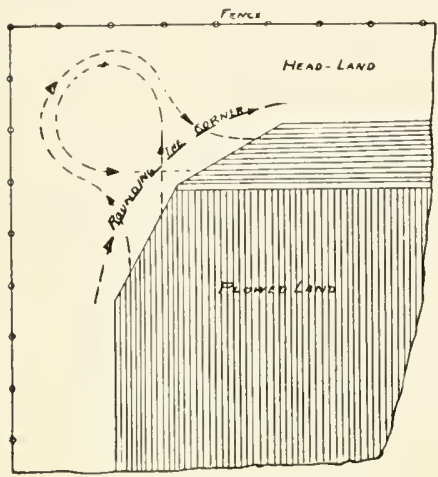

(Fig. 27)

How to finish plowing a field with a tractor. This shows the method of rounding the corners when plowing off the headlands. On the first two rounds it is necessary to make a complete circle at each corner as shown. plowing around the field. It is known as the dead-furrow method. The plows are not lifted in turning. The disadvantage of this is that a small crescent-shaped strip is left unplowed on each corner of every round.

The second is the backfurrow method. In this one the start is made at the center and the field is plowed by backfurrowing to the outside without raising the plows. The disadvantage of doing this is that the plows cut a narrower furrow when turning a corner than when driving straight and consequently there is a large triangular-shaped piece left at each corner of the field, which must be plowed with horses.

Either of these two methods is unsatisfactory if a good, thorough job of plowing is desired.

The case of disc plowing is different, however, than plowing with moldboards. The method shown in Figures 26 and 27 would not be at all satisfactory. A field should be plowed with discs in such a way that it will not be necessary to lift the plows. The best method to use is the back furrow method described above-starting at the center and plowing toward the outside.

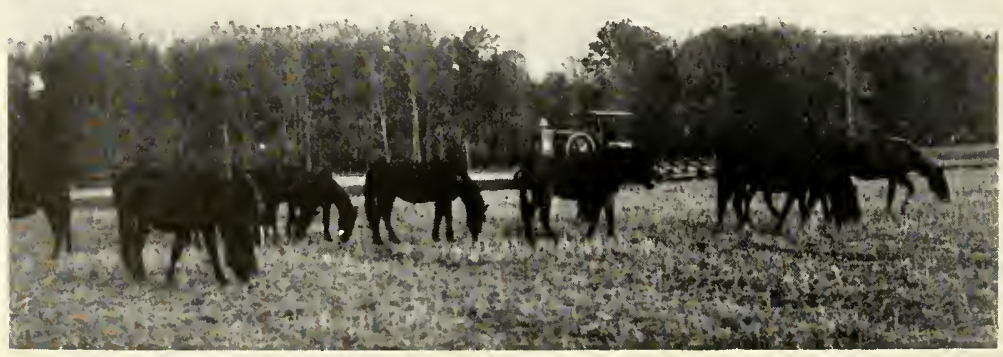

LET THE OILPULL PLOW (Fig. 28)

This illustration shows what the tractor is doing to the farm horse. This farmer is plowing much cheaper than he could with horses, and also much easier. In 1912 enough Rumely OilPull Tractors were sold to replace 60,000 horses. 


\title{
Tillage Operations and Seeding
}

\author{
ADVANTAGES OF THE TRACTOR
}

A

S HAS already been pointed out, thorough tillage is perhaps the most important of all the three fundamental factors which result in the largest crop yields. Let the work of tilling be done before rather than after the seed is put in the ground.

The proper preparation of the seed bed is of the utmost importance, and if more farmers could realize the extent to which it affects the yield, it is certain that more care and attention would be exercised. It is dependent upon two fundamentally essential things:

I. Soil and weather conditions.

2. Equipment.

The best soil and weather conditions should prevail to get the highest percentage of results. Also a first-class mellow seed bed is directly dependent upon machinery equipment.

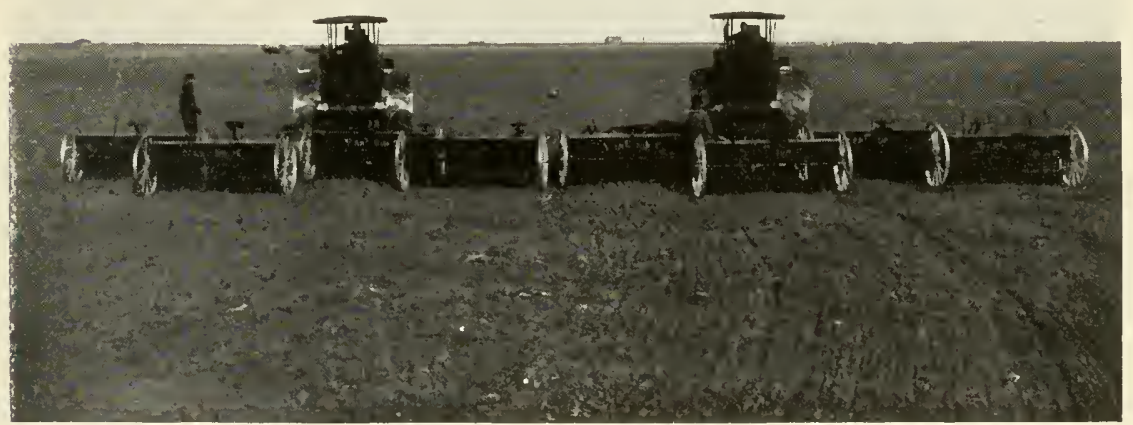

SEEDING ON A LARGE SCALE (Fig. 29)

One of the biggest problems on most farms is the matter of power. It is true in connection with the spring work more than at any other time during the year. If horses are used they lack the necessary endurance to rush the work as it should be. After standing idle during the long winter months their muscles have become soft. Consequently the work must proceed slowly to allow them to become hardened. At just this time usually is when the farmer desires to accomplish as much as he can in a short space of time.

The farm tractor has proved itself invaluable to the farmer as an excellent source of relief from worry and anxiety, particularly as regards spring work. It has provided him with sufficient power to carry on his work in the most efficient and effective manner. Its endurance is as good at the end of the season as it was at the beginning.

\section{HOW THE TRACTOR MAKES QUICK WORK OF SEEDING}

Formerly the farmer began his spring work early and finished it late. As a rule he was behind. The tractor has given it a much different aspect. He waits until the soil is in the best condition as to moisture. Then he goes 
on to it with his engine and other equipment. He works steadily all day and when night comes, another crew takes the outfit and keeps it moving until morning. It is stopped only long enough for supplies.

In this way spring work is completed in just half the time. The seed is put into the ground when it should be, and at harvesting time he finds that his labors have been rewarded by bigger and better yields.

The proper season for seeding is short. With a capacity for doing a large volume of work in a short time the farmer not only takes advantage of the best conditions of soil and weather, but also the time between each operation is greatly lessened, thus reducing to a minimum the evaporation of soil moisture. The work is done when conditions are best for doing it and is done rapidly.

Here is another point of advantage possessed by the tractor in this connection. It enables the famer to seed a larger acreage than when using horses, simply because his engine will supply from two to three times the power of the number of horses that equal its normal capacity.

\section{ELIMINATING THE PACKING EFFECT OF THE TRACTOR}

It is frequently claimed that the use of an engine on plowed ground

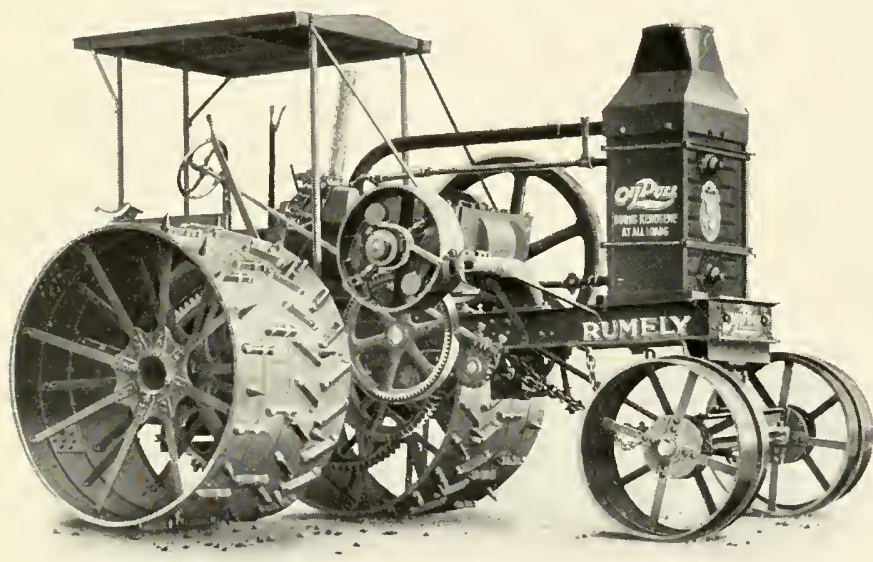

EQUIPPED FOR SOFT GROUND (Fig. 30)

An OilPull Tractor equipped with extension rims for the wheels will pull a load in soft ground where horses cannot be worked to good advantage. With these extra rims the packing effect on soil that is to be seeded is so small as to be in no way an objection.

effects from the packing of the drive wheels. The pressure exerted by the weight of the engine on each square inch of the wheel surface in contact with the ground at one time is no greater than the pressure of each square inch of a horse's hoof in contact with the ground at one time when it is walking.

In case the soil is at all wet it is advisable to use extension rims on the drive wheels. It may be desirable to use them at all times when using the engine on certain kinds of soil. Much, of course, will depend upon the nature and condition of the soil. The owner by a little experimenting will soon be able to determine when and where to use them. When traveling through plowed ground it is always a wise plan, whenever possible, to have a double-throw disc harrow, properly weighted, following behind the engine to break up the track of the wheels and pulverize the soil. Especially is this an advantage in soil that is inclined to be a little wet. The ground will not dry out as quickly and if seeders or drills are to follow all the grain will be put in at a uniform depth. 


\section{Equipment for Seeding and Tillage}

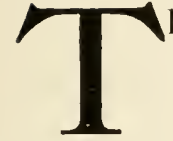

HE most important implement which goes to make up the power farmer's equipment is the disc harrow. If it is used as much as it should be, it will pay for itself perhaps sooner than any other implement on the farm. There are many times during the year when it can be used to good advantage.

\section{THE VALUE OF THE DISC HARROW}

Comparing the single-disc with the double-disc harrow, the latter is by far the more efficient tool to use of the two, as it leaves the land more level and smooth after its use than does the single disc. While it takes considerable power, it tears up the ground in a much better shape and gives a more thorough pulverization of the soil.

Where horse power is used the disadvantage is that it requires too much power to operate it. but with traction engines it has considerable preference over the single-disc type. Half as many machines are required, as the double-disc is two harrows in one. Consequently it is easier and more convenient to handle them behind the engine. Furthermore, it is cheaper than two single-discs.

As a means of pulverizing the top soil and forming the dust mulch the disc harrow is unequalled. It is thoroughly established that the disc should precede, as well as follow the

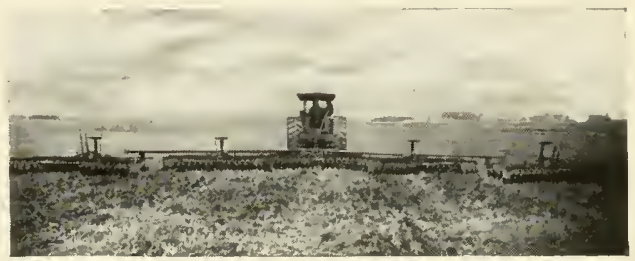

\section{AN OILPULL TRACTOR SAVING}

TIME AND MONEY (Fig. 31)

This outfit is getting the upper hand of the elements. Fast. quick work as shown here preserves the treasured moisture for the coming crop and insures bigger yields at harvest. plow. especially in the semi-arid regions. When land is disced before being plowed, the mulch formed holds the soil moisture for the coming crop. The presence of this moisture makes plowing easy and keeps the ground in plowing condition.

When plowing is done in very wet or very dry land, large clods are frequently left which can he very easily broken up by the use of the disc harrow. It is quite advisable to use the disc before seeding as there is no better tool for making a mellow seed bed.

\section{OTHER TILLAGE MACHINES}

At the present time the spike-tooth or smoothing harrow is the most universally used of all tillage machines. This is no doubt true to a large extent because it requires less power than the disc harrow. It is a valuable tool to use behind a disc harrow or drills in making a dust mulch. When it is not advisable for the disc to follow the gang plow, a smoothing harrow should be used to break up the clods to fill the open places in the soil in order to cut down the evaporation to a minimum.

Other implements for use with traction engines are the sub-surface packer which is a particularly useful tool in dry-farming sections, and the springtooth harrow which is adaptable for use in stony ground where the disc harrow would be of little use. Besides these are sod packers, crushers, rollers and pulverizers.

The selection of tillage tools depends upon the types of soil and climatic conditions. It is not the intention here to discuss when and where each 
tool should be used. The farmer from his own experience, or from that of his neighbor, is in a better position to best judge of the machines which are especially suited to his locality.

\section{DRILLS OR SEEDERS}

The principal difference between a drill and a seeder is that the former places the seed in the ground at practically a uniform depth, while the latter distributes it over the top of the ground where it must be worked into the soil by means of cultivators or harrows. In certain types of tough heavy soil, seeding by the use of the broadcast seeder is the most practical way, but where it will work successfully the drill is rapidly coming into universal use. It has the advantage in that it sows all the seed at about the same depth so that all of it germinates at the same time. Also, less seed is required, as it is more sure to grow, than when sown broadcast on top of the soil to be harrowed in.

As to the different types of drills, the single-disc drill is the more universally used, as it gives better results under a greater variety of conditions than any other.

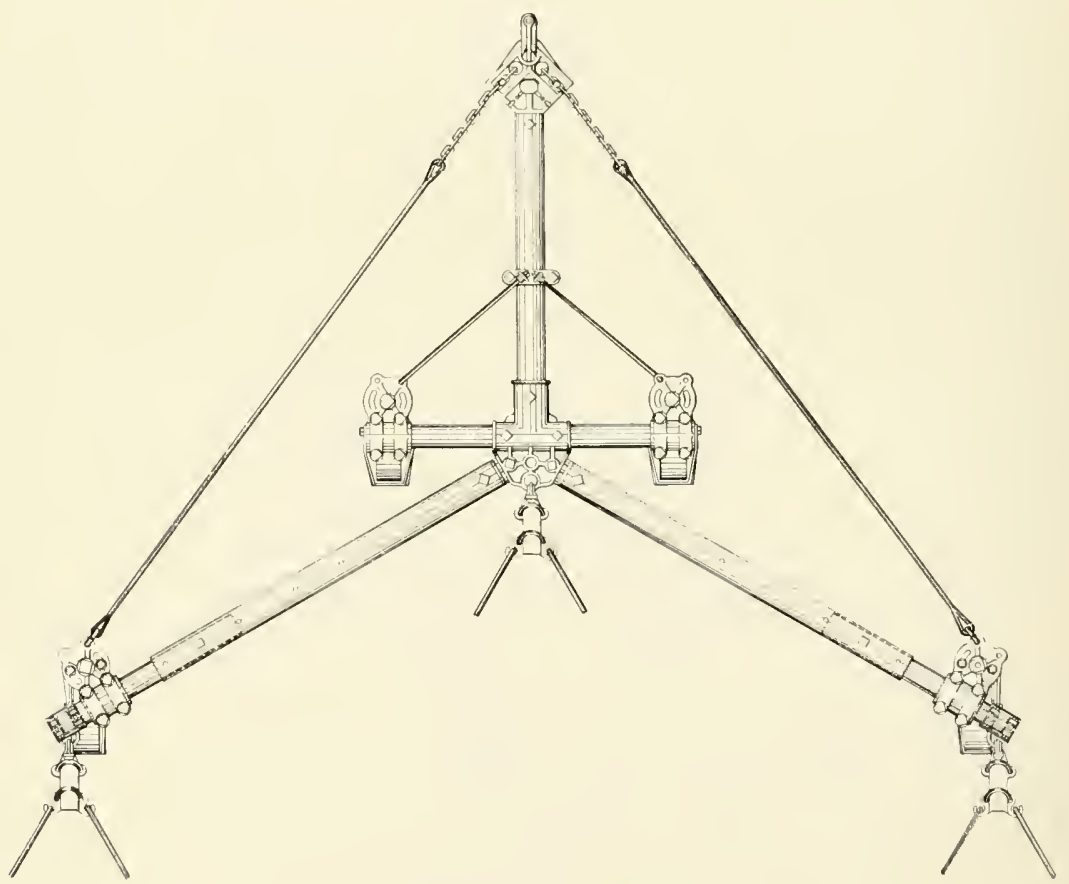

(Fig. 32)

This hitch is the same as one shown in Figurc 43, cxcept that it is changed to haul three drills or disc harrows instead of five. It makes a very good hitch for use with the smaller sized tractors.

Are you free with the use of lubricants? Don't forget that oil is cheaper than iron every time. Use more oil and you will have less trouble. Tractor owners, particularly, seem to have considerable difficulty in finding all the cil holes and grease cups on their engine. It pays to spend an extra half-hour or an hour each day to see if the machines you are using are thoroughly oiled and greased. Lack of lubrication not only destroys the machines, but requires much more power to haul them. 


\section{Hitches}

W

ITH the exception of the engine gang plow the same types of farm machines are being used with tractors that are used with horses. The principal change made in this direction has been to build them stronger and heavier in construction to withstand the greater wear and tear occasioned by use with the more powerful tractor. This has been necessary, as experience has taught both the farmer and the manufacturer that the machines designed for use with horses are too light.

In order to load the tractor to its normal, full-load capacity it is necessary that a number of machines be hitched behind it at one time, and in this connection we find one of the greatest problems of the traction engine user - the lack of the necessary equipment for hitching different machines to the engine.

It has been necessary for the farmer to build make-shift devices which are crude, awkward and cumbersome, and which greatly decrease the efficiency of the whole outfit. It is no easy matter to construct a home-made

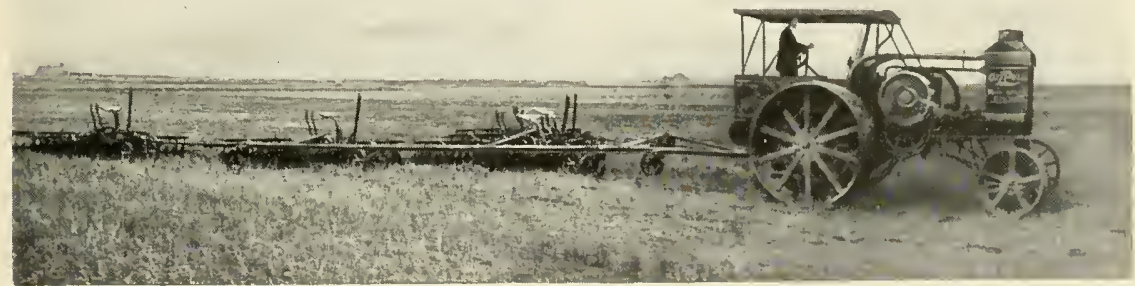

ONE HUNDRED ACRES A DAY (Fig. 33)

A Rumely OilPull Tractor $(30-60$ h. p.) is shown here hauling five 8 -foot double disc harrows by use of the Rumely-Hansmann drill hitch. It is discing a strip 40 feet wide and covering 100 to 125 acres each day. With this outfit the farmer can easily and quickly disc his ground in the Spring before plowing, which saves moisture and makes plowing much easier,

hitch that will work successfully, as the farmer's workshop is usually an almost negligible quantity and he lacks the proper material to work with. Throwing something together to serve the purpose of a hitch always brings no end of trouble and a waste of valuable time.

\section{ESSENTIALS OF A GOOD HITCH}

It is good economy to use the best hitches for increasing the working efficiency of the tractor and all of the machines that are being hauled behind it. A well-designed, well-built hitch decreases the amount of wear and tear on the whole outfit and aids greatly in improving the quality of the work done.

A good efficient hitch should include the following essentials:

$$
\begin{aligned}
& \text { I-Convenience } \\
& \text { 2-Lightness } \\
& \text { 3-Durability } \\
& \text { 4-Adaptability } \\
& \text { 5--Flexibility. }
\end{aligned}
$$

In the first place a hitch should above all be convenient, and so designed that it will be a simple matter to attach to or disconnect the engine or ma- 
chines from it. It should be easy to manipulate. Durability is essential because of the excessive strains which naturally result when a number of heavy machines are hauled behind an engine. At the same time it should be of as light a construction as possible in order not to greatly increase the draft of the outfit and to make it easy to handle when not in use or when getting an outfit ready for work. It should be easily adapted for handling as many different machines as possible and also to work under many different conditions. As to flexibility it must conform to the surface of the ground easily, and in turning no undue strains should be put upon it, the machines which it is hauling, or the tractor itself.

\section{A GOOD DRILL HITCH}

In Figures 32, 36 and 43 are shown a drill hitch which fulfills the above requirements more fully than anything which has been so far devised. It is called a drill hitch for convenience, but it is equally well adapted to the several different kinds of seeding and tillage machinery.

It is a very convenient hitch. The different machines are easily attached to or disconnected from it. This is a very desirable feature, as it frequently happens in certain sections and at certain times of the year that in soft ground or in wet spots the engine becomes stalled with its load and it is necessary to disconnect it from the rest of the outfit. With a hitch as shown in the illustration all that is necessary is to pull the clevis pin in the engine drawbar, run the engine on ahead until firm ground is reached, then by means of a cable or chains the outfit can be hauled across.

Farmers, especially on the smaller farms, of tentimes find it an advantage to take the engine from the field at night to the farm buildings for supplies, where it can more easily be cared for, repaired or overhauled. With this hitch the engine can be easily disconnected and the rest of the outfit left standing.

The hitch is not so heavy but that one man can move it around from place to place on hard ground. This makes it very convenient when it is desired to put it away under shelter or when assembling an outfit of drills or tillage machines for work in the field.

Whenever it is to be used in fenced fields and the hitch is to be taken through an ordinary gateway all that has to be done is to disconnect the long draw rods between the tongue and the flaring wings, and the two wings will swing together permitting it to be hauled through the opening.

\section{A HITCH SHOULD BE LIGHT AND DURABLE}

Another advantage of this hitch is that lightness and durability are combined. An engine hauling a number of machines at one time naturally brings severe strains on it and consequently great strength is desired. Steel pipe and malleable iron castings are used throughout. The strong draw rods which are used take practically all the strain due to the draft of the implements. The fact that it is light is shown by the statement made above that one man can move it where desired on hard ground.

This hitch with its flaring wings has the advantage over the straight drawbar hitch in that undue strains on the equipment are very largely eliminated.

One very desirable feature which this hitch possesses is that it is easily adapted for hauling all kinds of seeding and tillage machinery. The matter of attaching the different machines is very simple. It is also suited for hauling a combination of different machines in tandem or separately. 


\section{A GOOD METHOD TO FOLLOW}

One farmer's plan of discing and seeding is as follows: He uses a fivedrill hitch like the one illustrated in Figure 43. In the center he places an eight-foot double-disc harrow and two more just like it on one of the wings. To the other wing he fastens two twelve-foot drills. In this way the soil that is double-disced on one round is seeded on the next.

This type of hitch with practically no change whatever can be made to haul packers, crushers, rollers, cultivators, harrows, etc. This feature alone makes it a very valuable addition to a man's power-farming equipment. When properly hitched to the wings the machines keep their alignment at all times.

When compared to some home-made affairs, the hitch under discussion is a mighty flexible one. The wheels on the truck are castors which allow the outfit to turn very sharp corners. In turning, the drills or other machines do not bunch up or touch one another but will turn about, each one coming in its place as the engine leads. The outfit can be turned as sharp a corner as is possible to do with an engine and in doing so there will be no undue

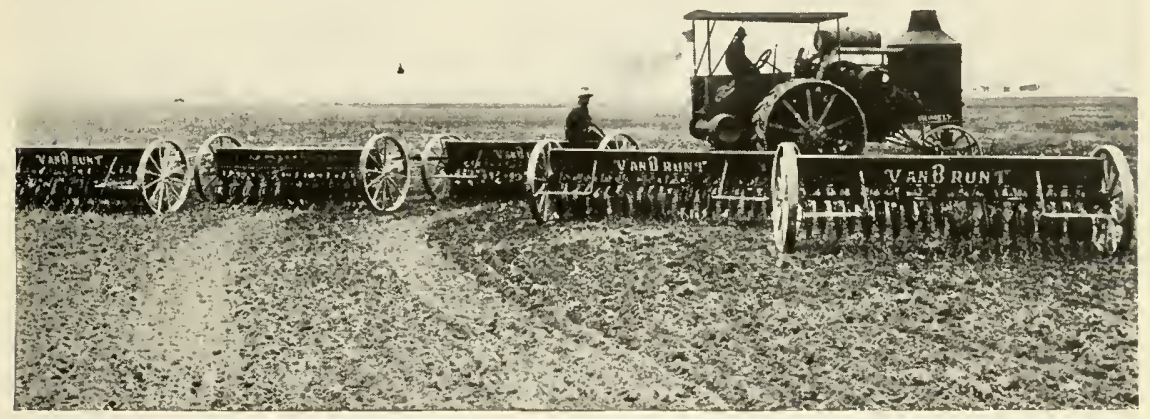

A SHARP TURN WITH A RUMELY-HANSMANN DRILL HITCH (Fig. 34)

strains upon any of the equipment. The best plan in turning, however, is to let the inside wheel of the implement at the center of the turning circle act as a pivot about which the whole outfit is moved. (See Figure 34.)

This hitch is well adapted for working in uneven ground as it adjusts itself readily to variations in the surface. 'The outer end of the wing of the five-drill hitch may be raised vertically ten feet from the ground. It can also be dropped vertically the same amount.

\section{A GOOD FEATURE}

The tendency to skew to one side or the other is very slight when the load on one wing is different than the other. This was well illustrated in connection with an outfit in which an engine was hauling five double disc harrows set to cut full depth. The discs on one of the outside machines were set straight. This reduced the draft by about $8 \mathrm{~h}$. p. on that side of the outfit. The difference with which the light side pulled ahead of the heavy side was so small that it could not be detected with the eye.

This goes to show that drills or discs of different sizes may be used with this hitch with good success. It is only necessary to have the load balanced as nearly as possible as it naturally gives the best results in any case. But if there should be a difference of draft on either side, the operation of the outfit will not be materially affected. 


\section{Methods of Seeding}

\section{I.AYING OUT THE FIELD}

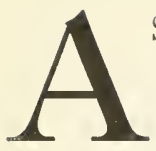

$\mathrm{S}$ in plowing, the way in which the field is laid out is very important. When this is improperly done it very frequently results in a vast amount of lost time and inconvenience. There is a right way and a wrong way, and the easiest way is the right way.

The best plan in seeding a field is to do it in such a way that it is not necessary to lift the drills except to free them from trash or something of the sort.

There are two different methods of seeding a field with a tractor outfit. The first is to begin at the outside and work toward the center by driving around and around. The disadvantage of this method is that it leaves a narrow strip unseeded on each corner of each round. These strips can be left either unseeded or may be seeded by driving up and down each corner of the

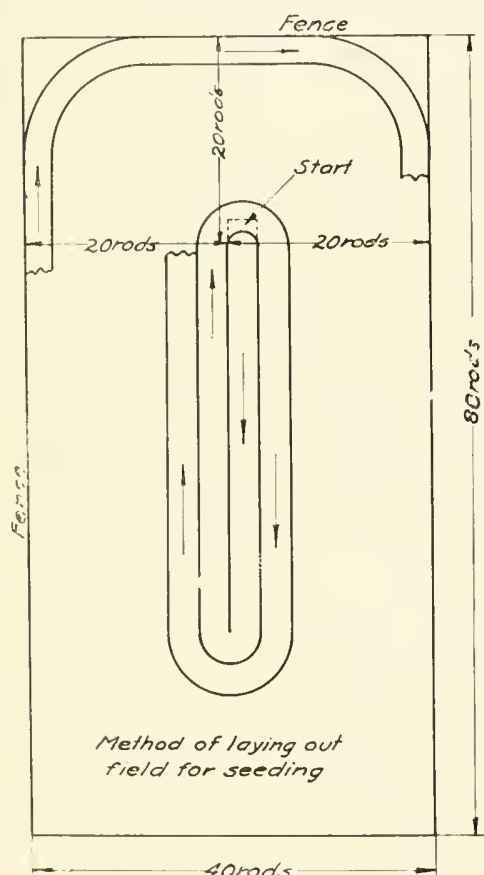

(Fig. 35)

Properly laying out the field for seeding insures a better job and saves a great deal of time.

field. If they are left unseeded they will grow up to weeds, and if seeded there is considerable land at each corner which receives a double amount.

\section{THE BEST METHOD}

The second method is to begin at the center of the field and work toward the outside by driving around and around as illustrated in Figure 35 . The field shown is So rods long and 40 rods wide.

The first thing that should be done is to set two guide stakes at each end, each of which should be 20 rods from the end and both sides of the field. The operator should begin seeding at one of the stakes and drive in a straight line to the other, then turn and drive back on the other side of the line, and so on. The idea is to "backfurrow" the field from the center to the outside. In starting, the drills should be dropped in a short distance before the first stake is reached so that no land is left unseeded when making the turn at the finish of the first round.

When the stake at the opposite end is reached, if the hitch in Figure 43 is used, the drill wheel next to the stake should act as a pivot for making the turn. The operator should exercise considerable care to see that it is executed properly. This will be the only sharp turn in the field, and the succeeding ones will become more gradual at each round.

The principal objection to this method is that it leaves a rather large triangle unseeded at each of the outer corners, but it does not leave unseeded strips when making turns at the corners. The outer corners of the field can be sown by hand and disced in with horses, or in can be seeded by a team and drill. They should be left somewhat rounded, however, to facilitate the work of the harvesting outfit. 


\section{A MARKER FOR SEEDING}

When seeding with a large outfit it is very desirable to have a mark for the operator to follow after the first round. Setting guide stakes for this purpose takes considerable time and is far from satisfactory. The most practical way is to have a marker on the outfit which will extend the proper distance to one side for making a mark on the plowed ground that can be followed on the next round. Figure 36 shows a method of accomplishing this. In this outfit five ten-foot drills are used. In order that no ground will be seeded twice or any skips made the guiding is done by means of a

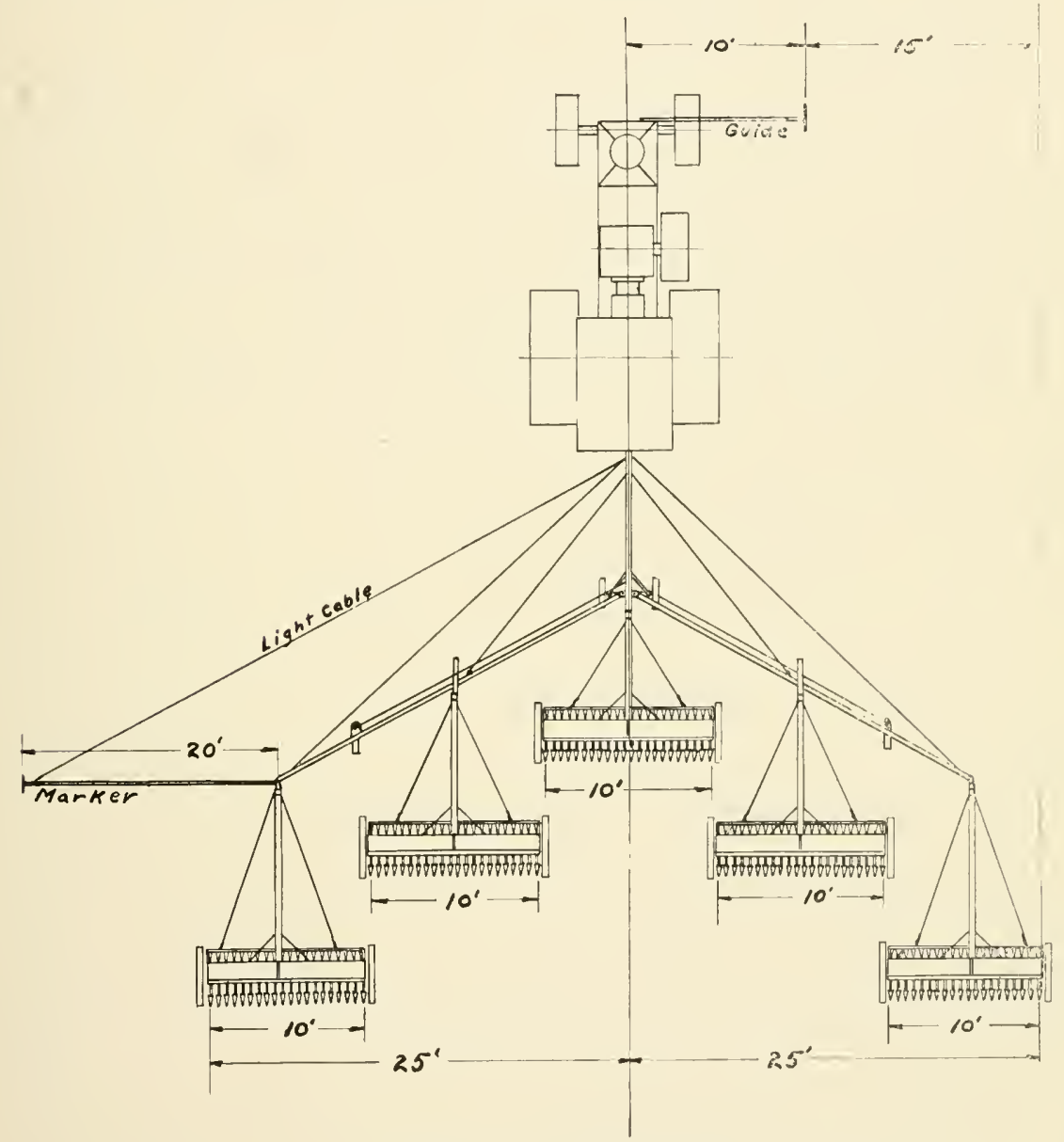

A SEEDING OUTFIT (Fig. 36)

This ground plan shows a method of using a marker in connection with see ling and how the drills are attached to the Rumely-Hansmann drill hitch.

"marker" attached to the hitch and extending to one side, usually to the left, and a "guide" on the front of the engine extending to the opposite side or to the right.

The marker consists of a one-inch to a one and one-half-inch wrought iron pipe, the size depending more or less on the ground conditions. If the ground is rough, use a larger pipe. If smooth, a smaller size will answer the purpose. About six inches of the end of this pipe is placed in the end 
of a wing section of the drill hitch, which is the same hitch as shown in Figure 43. The pipe is held in place by a clamp, or bolt through both pipes. This end can he hent so that the marker will be at right angles with the direction of travel or it can be in line with the wing section.

To the outer end of the marker should be clamped a cultivator shank and shovel or some convenient device for making a mark on the surface of the ground. The size or depth of this mark will depend upon the conditions of the soil. In case of rough ground it may he necessary to add a weight to the outer end of the pipe to make a mark that can be plainly seen on the next round. At or near the outer end of the marker should be fastened a light cable, the other end of which should be connected to the tongue of the hitch. This cable takes the bending strains off the pipe and prevents it from being twisted out of shape. It also holds it steadier, thereby making a more even mark.

A marker so constructed can be very easily slipped out from one end of one wing section and inserted in the other on the opposite side. In this way it can be used on one side of the outfit as well as the other.

The guide on the front of the engine can be made from a lighter pipe. The distance which it extends from the center of the tractor must be determined to suit the convenience of the operator. At the end an elbow and a short length of pipe may be screwed on so that it will reach within about a foot of the ground.

The working of this arrangement is this: The outfit shown in the illutration is seeding a strip 50 feet wide at one time. The distance from the center of the engine to the last drill mark on the previous round is 25 feet. We will assume for convenience that the marker is 20 feet long measured from the drill tongue. It then extends out i 5 feet from the last drill mark. Also assime that the guide on the engine extends out in the opposite direction so feet from the center of the engine. By guiding the engine so that the end of the guide will travel directly over the light furrow made by the marker on the round hefore, no skips or laps will be made between the various rounds.

The object of using the guide on the front of the engine is to make the marker as short and less cumbersome as possible. Their lengths can be changed to suit the width of the strips sowed and for greater convenience of operation.

\section{CARRYING THE SEED}

With an engine outfit we have the advantage in that the seed may be carried on the equipment with a small addition to the total draft. This is not the case when using horses. The best plan for carrying the seed is to haul a wagon containing sacks of grain behind the center drill. A low platform wagon is best. It should be in such a position that it will be, as nearly as possible, the same distance from each drill.

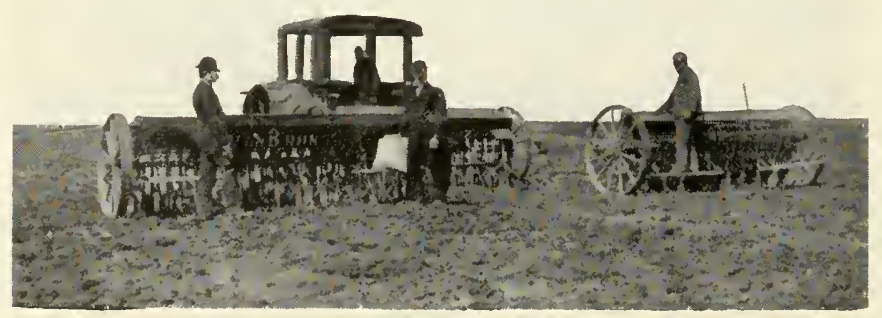




\section{The Tractor in the Harvest Field}

HE man with a sickle had a hack-breaking job and made slow work of gathering the harvest. A six-foot binder takes the place of forty men with sickles and one man drives it, but even the modern binder hauled by horses is handicapped, however, because it must be used in the hottest part of the summer and should be used every possible moment in order to gather the crops when the weather is fair and when the quality of the grain is at its best.

This involves power, and with all his excellent qualities the horse is unable to endure the work of the harvest for more than from six to eight

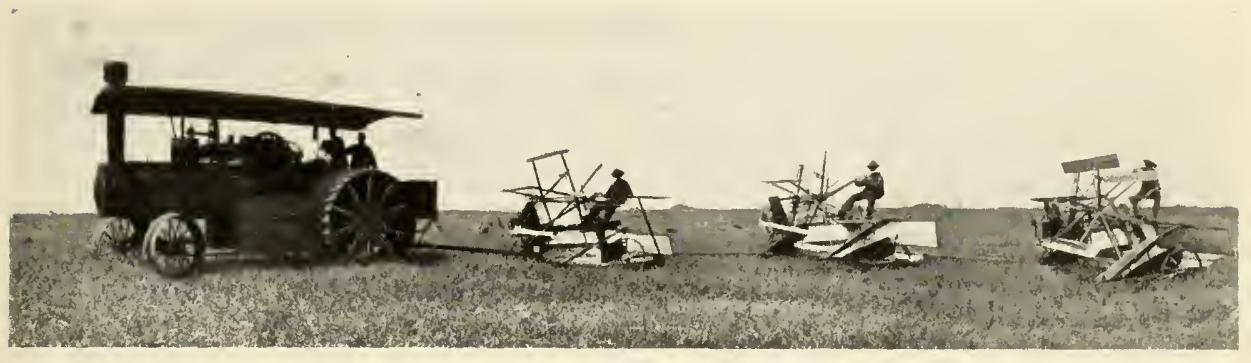

THE FIRST STEAM HARVESTING (Fig. 38)

This picture shows the first steam tractor used in the modern way to pull binders. Now the patent binder hitch (Figure 45) is in universal use, adding 10 to 15 days each year to the use of hundreds of tractors. This Rumely steamer and binders were used to cut the 1909 crops of J. A. Mullarkey, Windmere, N. D., who was the first purchaser of the now famous Rumely-Hansmann binder hitch.

hours, so the farmer fails in getting the most out of his binder. Without several shifts of teams the binder is apt to lag toward the end of the day and do a poorer quality of work.

Many farmers are taking care of the rush seasons of seedtime and harvest by selling three-fourths of their horses and putting the money into a general-purpose farm tractor. This combination solves the problem very nicely. Just enough horses are kept to do the light work about the farm and instead of a great many of them lying idle during the winter months, a few are kept moderately busy the year round.

The tractor with its capacity and endurance makes it possible for the farmer to harvest his grain when it is in the proper condition. Every farmer appreciates how important it is to have his grain cut and bound at just the right time. Delays in the harvest field are dangerous. A few hours of hot winds or a ten-minute hail storm means sure destruction to the crop. When the grain is just ripe enough it must be cut as quickly as possible.

The tractor works best in the hottest weather. It is a tireless beast and will work steadily as many hours per day as desired. It need only be stopped for the necessary oiling or adjustments on the equipment. It enables the farmer to harvest his crop quickly just when conditions are most favorable. It insures him against the loss of his entire season's work. It also eliminates the uncertain and expensive factor of horses from the problem of harvesting.

\section{EQUIPMENT FOR HARVESTING}

The farm tractor hauling a train of grain binders is the latest step in the development of the methods of harvesting. Today we may see an engine hauling from two to eight binders at one time and cutting a swath of a rod to four rods in width. To do this it is necessary to provide a special hitch 
which will not only allow easy turning but will secure perfect alignment of the binders so that they will cut a full swath. On rolling ground the number of binders is limited by topography rather than the power of the engine.

The right-hand binders are perhaps the best to use as the steering wheel is usually on the right-hand side of the tractor, which allows the operator to guide his engine better and to keep it at the proper distance from the grain at all times.

The header, a wide machine that cuts the wheat stalk close to the head and elevates it without binding, has a much greater capacity than the binder. It can be used profitably only when the absence of storms allows the grain to remain on the stalk until fully ripe. One of these can be quite successfully operated ahead of a small tractor. In some cases, a larger engine will use a header in front and plows or disc behind.

The combined harvester cuts, threshes, and sacks the grain at one operation. This machine drawn by a large tractor may place from 75 to 125 acres of wheat in sacks ready for shipment in a day of twelve hours. The disadvantage is that the crop has small protection from unfavorable weather. Rain may beat it down and shell out part of the grain or the wind may place it beyond the reach of cutting. It also scatters the weed seeds over the land.

\section{THE BINDER HITCH}

In Figure 45 is shown a binder hitch which is used for hauling binders in tandem and in multiple. The number which can be hauled by this method is dependent only on the power of the engine. It will handle

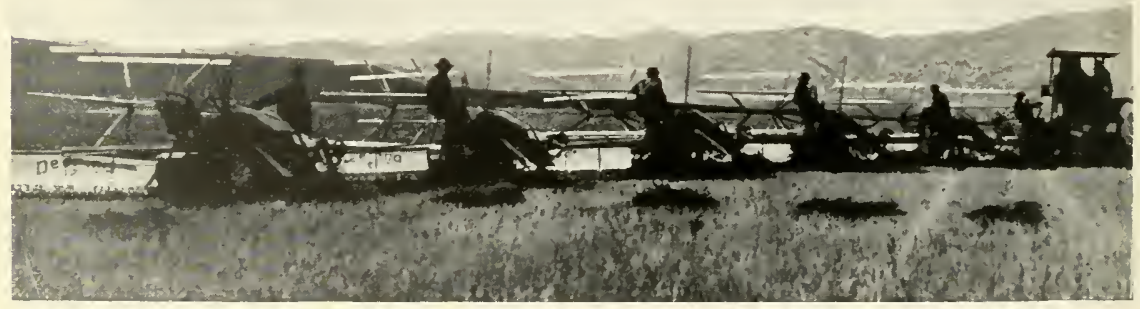

AN OILPULL TRACTOR IN THE HARVEST FIELD (Fig. 39)

The Rumely-Hansmann binder hitch has made possible harvesting on an extensive scale by the use of the tractor. This outfit harvesting at the rate of 120 acres per day enables the farmer to cut his grain when it is in the very best condition. This picture offers a suggestion of how a number of farmers can combine their binders behind one engine as shown and harvest their grain much quicker and cheaper than they can with horses.

machines of any size or make. It is made from steel and malleable castings, hardwood timber and heavy gas pipe.

The principal feature of this hitch is an offset steering pole (Figure +5). The man on the binder by turning the tiller wheel offsets the pole more or less as desired, by which it is possible to make the binder take any width cut. Each binder works independently of the one in front of it. If one machine is in need of repair or adjustment, the operator simply turns the offset out of the pole until the binder trails directly behind the one in front of it. After the changes are made it is then ready to take the grain again. 
The hitch can be converted with very little trouble from a right-hand to a left-hand hitch.

When several binders are hauled behind a tractor it has been found that the side draft effect is very small. This is due to the fact that the forward pull of the binder ahead has a tendency to counteract this side draft, except in the case of the last binder.

As an example of this, four binders in offset position were hauled behind an ordinary dray on hard ground. A cordwood stick was stuck in the grain wheel of each binder. The side draft even with these wheels skidding was not enough to skew the truck to one side.

In another instance a chain was substituted for the pole of the front binder and still they kept in line. This also shows that there are no

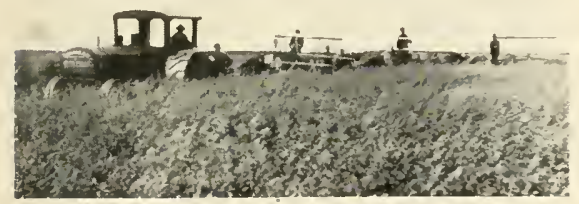

A GASPULL TRACTOR HARVESTING (Fig. 40 severe bending strains on the pole.

\section{METHODS OF HARVESTING}

In harvesting in a fenced field the best plan is first to cut a strip around the outside close to the fence. taking a full swath with all the binders. Then the direction of the outfit is reversed and the field is cut by driving around it.

Br using the hitch as shown in Figure 45 it not only allows easy turning as can be seen in Figure ${ }^{1}$, but it also gives perfect alignment of the binders so that each will cut any width swath desired.

In turning the corners a small strip of grain will be left by each binder, but this can very easily be cut by running up and down the corners after the field is finished. In this connection also, the man operating the bundle carriers on each binder should be careful not to dump the carrier at any time on the corner so that if it is desired to run up and down the corners before the grain is shocked it will not be necessary to spend any time moving bundles out of the path of the outfit. Shockers should also be cautioned not to set up shocks on the corners for the same reason.

When starting a field the engine operator should see to it that each corner is rounded off to such an extent that he will not have to make too sharp a turn with his engine. It should be just sharp enough so that the drive wheel will follow around

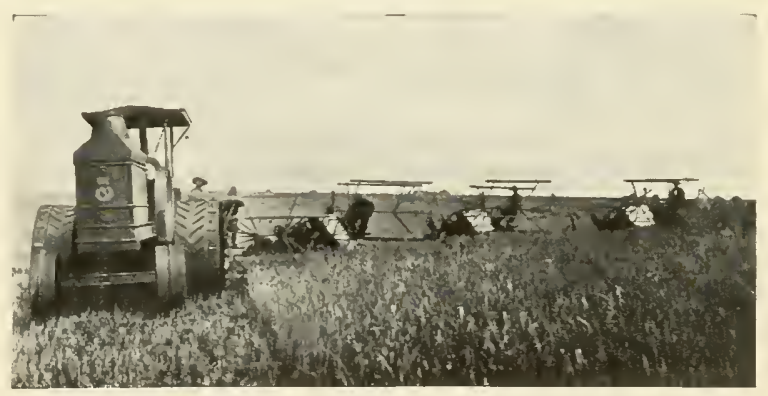

TURNING A CORNER (Fig. 41)

This show's how easy it is to turn a corner with a harvesting outfit when a Rumely-Hansmann patent binder hitch is used. The OilPull Tractor is hauling four binders with this hitch and cutting 70 to so acres a day.

close to the grain. This will also make it easier turning for the men on the binders. Figure $+\mathrm{I}$ illustrates this point very well.

It is a good idea to have a guide on the front of the engine extending out to the grain. The engine operator should drive his engine in such a way that this guide will just touch the edge of the grain at all times. It will be easier for him and also the men on the binders because if the engine is always kept at a certain distance from the grain the men on the binders will not have to use their tiller wheels so much and consequently they can 
give more attention to the working of the binder. The engine should be kept as close to the grain as possible without knocking it down.

With such an outfit it is a decided advantage to have a gong in the cab of the engine and a string running from it back to each of the binders. If any serious trouble occurs, or it is desired to stop the outfit for any reason, any one of the men on the binders may signal the engine operator by ringing the gong. It is also an aid to the engineer in that he does not have to watch the men on the binders for signals to stop in case they need to and he can keep a better lookout ahead.

It is a very good plan to have an extra binder available, then if one of the outfit becomes disabled in such a way as to need extensive repairs, it can be cut out and the extra one replaced for it.

\section{THRESHING}

In most sections threshing follows close on to harvesting. The tractor that has been used for plowing, preparing the seed bed, harvesting and many other jobs can now be belted to the separator and the grain threshed.

One of the problems of the farmer, who raises a large acreage of grain, is to get it threshed out when it is in fit condition. The lack of labor does not permit him to stack it and thus protect it from the weather. It simply must stand in the shock until it is hauled to the thresher.

If $i t$ is allowed to stand until the custom rig arrives, it all too of ten happens that a great amount of damage is done in the meantime. Farmers have lost thousands and thousands of dollars by having their grain crop partially or wholly destroyed while waiting for someone to thresh it for them. This misfortune does not fall upon the power farmer who has included a separator in his equipment.

Many men, sad to say, never think of locking the stable until after the horse is stolen. So it is with many grain growers. The loss in one season would have many times paid for the separator. The deterioration of the grain crop is more or less of a common occurrence, and every farmer should make provision to guard against it.

For the owner of the medium sized farm a separator means a big investment compared to his business. But a partnership or community machine involving a smaller sum of money for each man will solve the threshing problem practically as well.

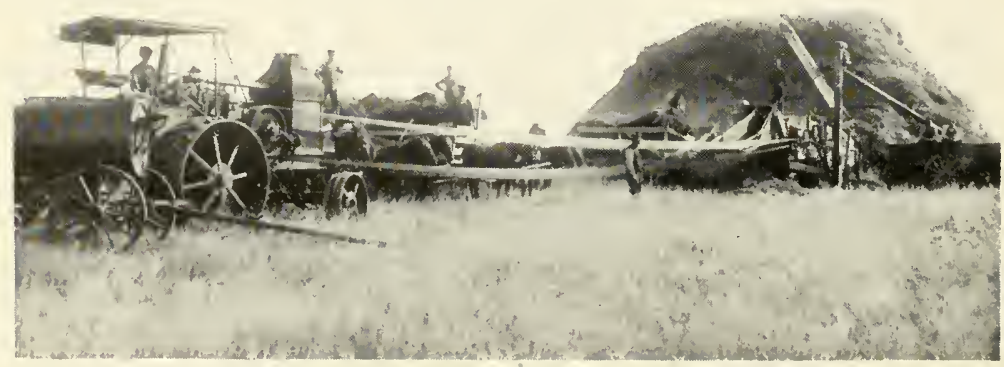




\section{Directions for Setting up and Operating the Rumely-Hansmann Drill Hitch}

$\mathbf{R}$

EAD these carefully before you assemble your machine and have the man who is to operate the hitch acquaint himself with these directions and instructions. The two wheels which carry the These bolts are to hold the wheels in a rigid position. They are interchangeable by removing the bolts and swinging the wheel around where proper holes will be found for the replacement of these bolts. Two wheels are not equipped with bolts in the wheel fork heads. These wheels attach to the carriage. At all times they should be free oscillating castors. It is important that the wing section wheels travel in a line parallel with the track made by the engine. To accomplish this: Loosen the bolts in the wheel fork head, start up the engine and the wheels will take their proper position. Then tighten these bolts good and tight. It is well to observe if these wheels are tracking properly, as probably the first adjusting will not be exactly accurate.

\section{FOR THREE DRILLS}

Replace the $181 / 2$-foot extension pipe $\left(D_{3} 6\right)$ by the $4 \frac{1}{2}$-foot pipe $\left(D_{32}\right)$. The first hole in the front section should be used when setting up for 12 -foot drills, the second hole for II-foot drills and the third hole for Io-foot drills. If smaller machines are used, close the angle of the wings accordingly by means of chains.

The holes in the fork (I07) permit the raising and lowering of the hitch. This is to enable the operat tor to so attach the hitch to his engine that there will be a straight line of draft. Avoid a downward pull on the hitch.

The drill tongue castings (No. 65) are slipped under the tongues and for the two outside drills are placed as near to the ends of the tongues as possible. The next two drills have the drill tongue castings placed about two feet from the ends, and the tongue casting for the middle drill should be placed about four or four and one-half feet from the end of the tongue. Hook tongue brace rods on the drill tongue castings and fasten chains securely around the frames of the drills at places where the chains cannot slide inwardly. When this is done, draw the drill tongue castings up towards the ends on the tongues and tighten the $\mathrm{U}$ bolts. This will tighten up the tongue brace rods and chains firmly. The shortest tongue brace rods are for the middle drill, the next size are for the second two drills, and the longest are for the outer drills.

\section{FOR FIVE DRILLS}

Set up the hitch as shown on page 44. This picture shows the telescoping of the wing sections to accommodate five Io-foot drills. For 12 -foot drills use the first hole in the end of the first wing section; and place the wheel three feet from the ends of the second wing section. For II-foot drills use the third hole in the first wing section and attach the wheel bracket about two feet from the ends of the second wing section. For Io-foot drills use the fourth hole in the first wing section and attach the wheel brackets about one foot from the ends of the second wing section. For 8 -foot and 9-foot drills use the last hole in the first wing section. The more minute adjustments can be made by the spreading or closing of the wings, in case there is any unplanted or replanted land. 


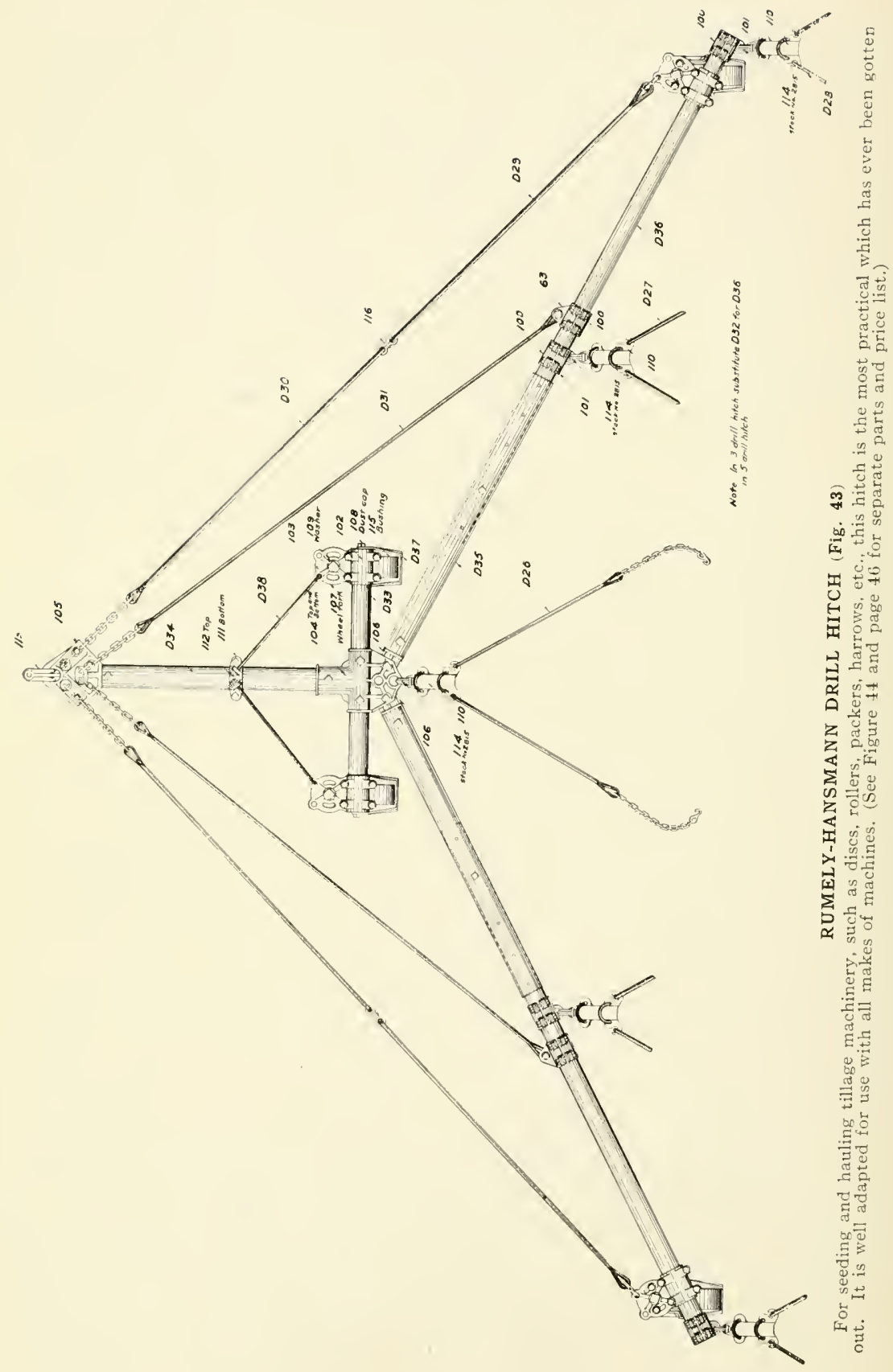




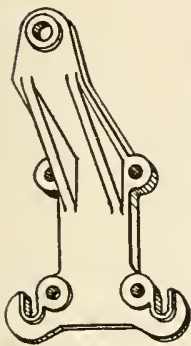

110
Q.

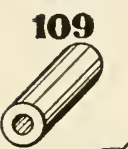

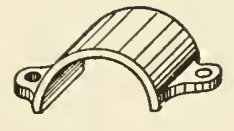

111

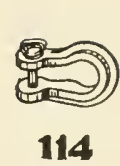

114

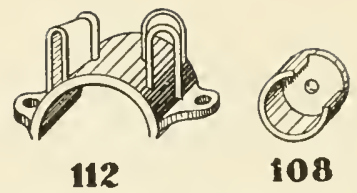

112

108

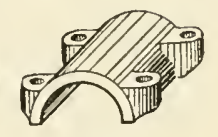

63

102
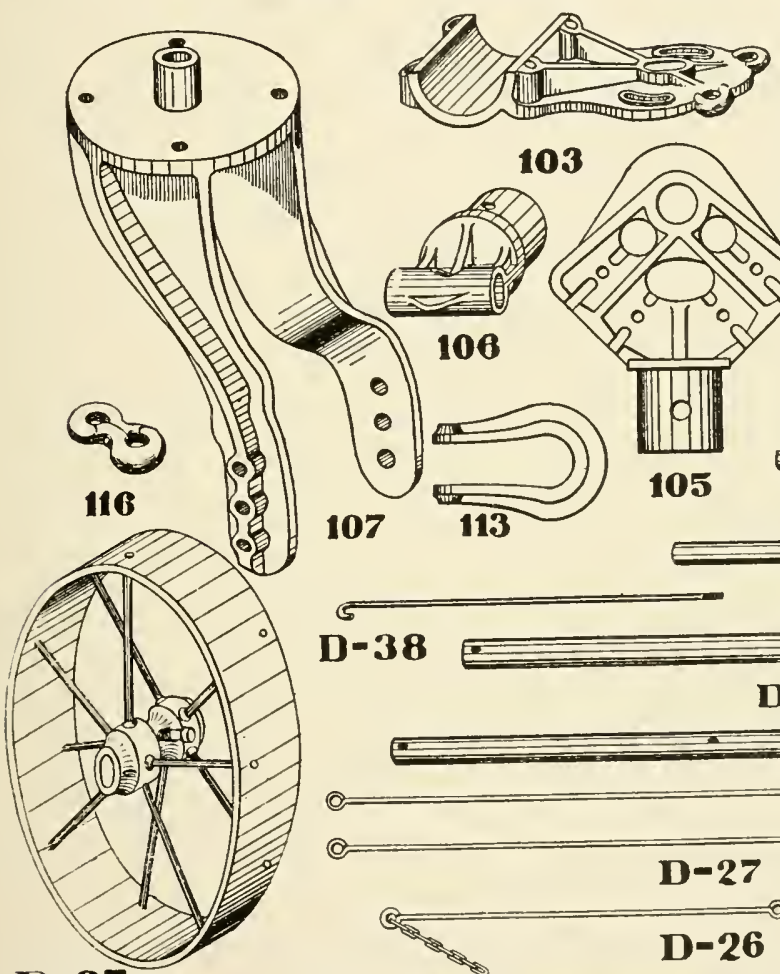

D-37 100
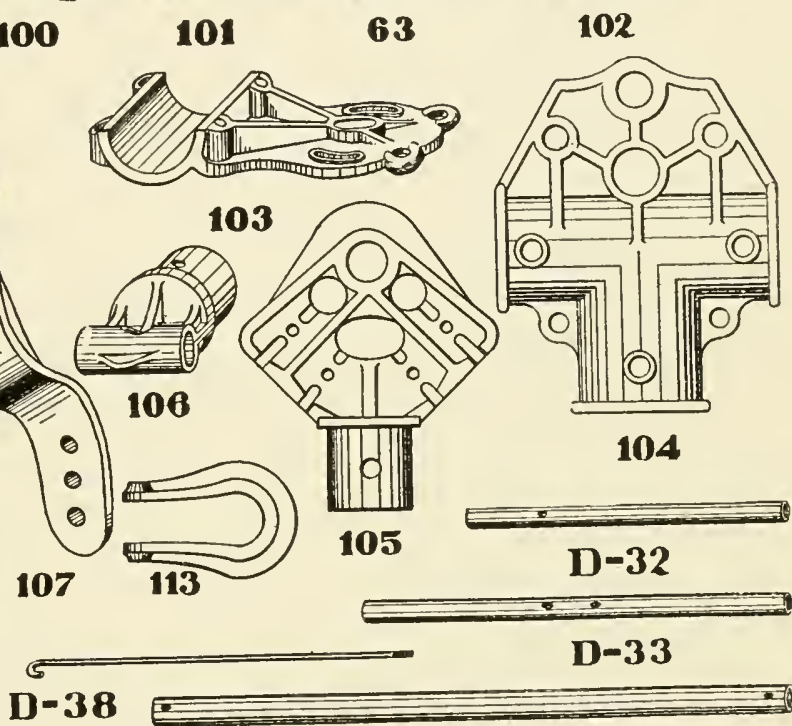

D-34

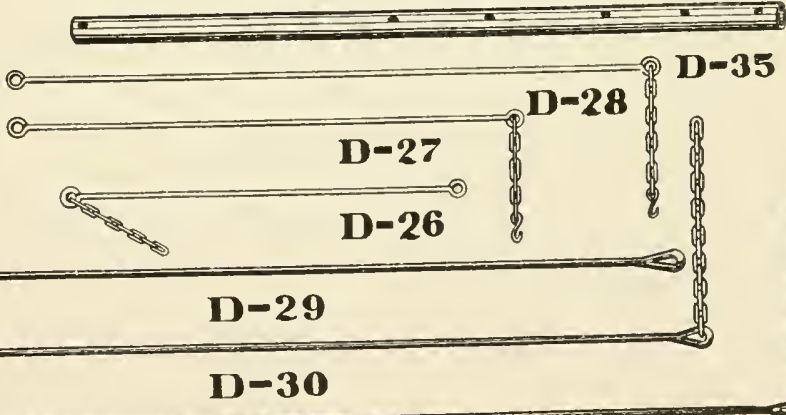

$$
\text { D-31 }
$$$$
\text { D-36 }
$$

(Fig. 44)

This cut shows the parts of the Rumely-Hansmann drill hitch (see Figures 32 and 43). 


\section{Parts of No. 2 Rumely-Hansmann Drill Hitch}

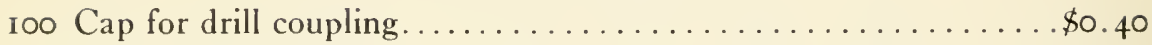

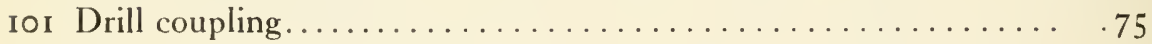

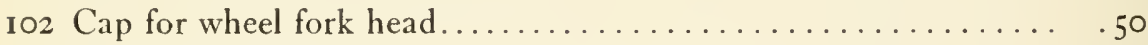

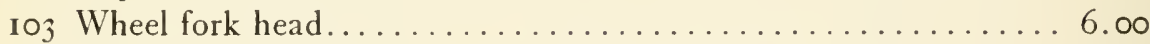

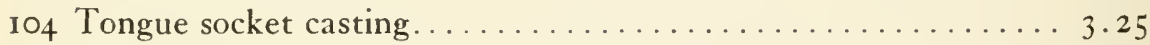

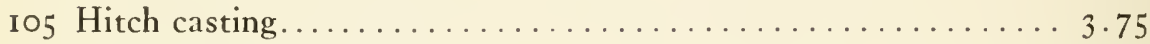

ro6 Coupling head for wing.....................

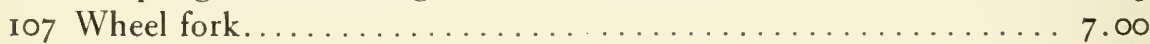

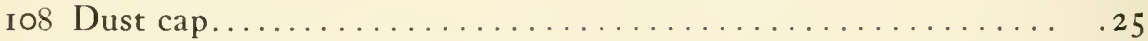

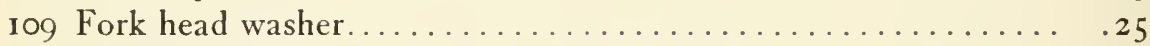

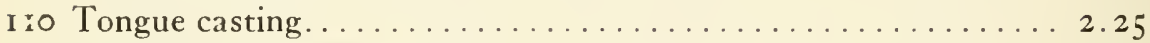

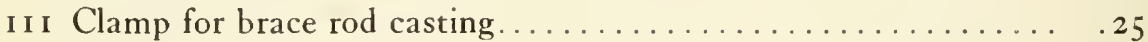

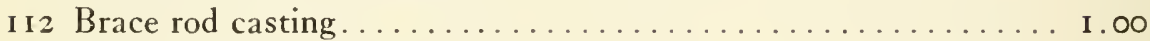

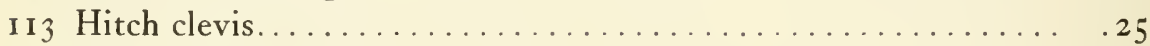

II 4 Drill coupling clevis......................... I5

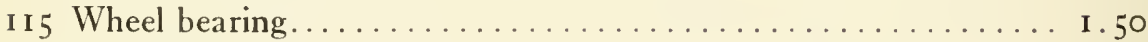

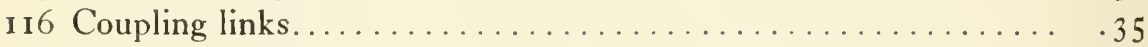

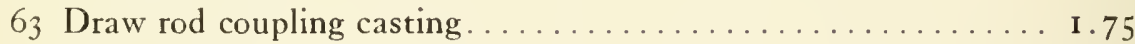

D26 Short tongue brace rod.......................... I

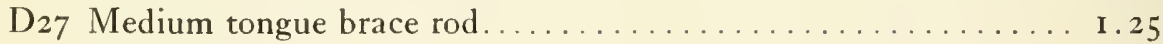

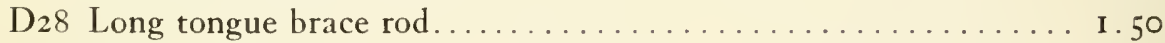

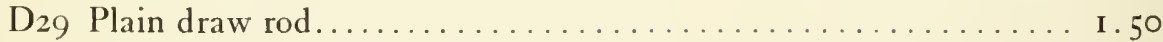

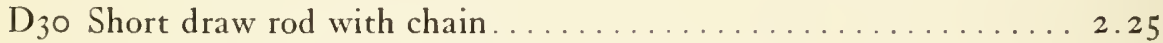

$\mathrm{D}_{3}$ I Long draw rod with chain.......................... 20

$\mathrm{D}_{32}$ Wing section (second) for three-drill hitch............... 2.00

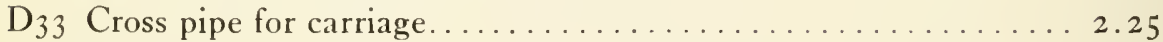

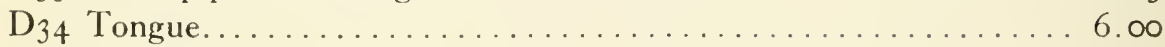

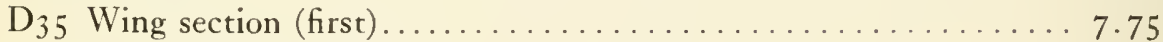

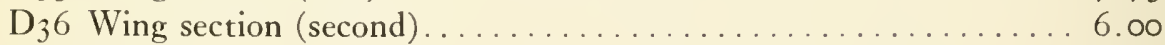

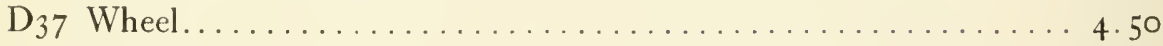

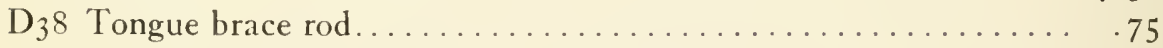

In ordering extras give name and number to facilitate prompt shipment.

Sun and water are the worst enemies of a farm machine--even more so than the wear and tear of service in the field. Increase the life and usefulness of your machinery by providing a dry, snug shelter and giving it a coat of paint each season when you have finished using it. It is unprofitable to leave implements out-of-doors to be rotted and rusted by the elements. Would you leave dollar bills scattered around on your farm exposed to the thieves of Nature? No? Well, there is not a particle of difference between that and leaving tools, which you have paid good money for, under trees and in fence corners the year 'round. The man, who does that, is far from knowing the real value of a dollar. It is the same old principle-"a dollar saved is a dollar earned," and there is many a farmer who can save a lot of dollars each year by properly caring for his machinery. 


\section{Directions for Setting up and Operating the Rumely-Hansmann Binder Hitch}

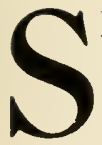

ET up the hitch as shown in Figure 45, then follow these directions about attaching. Attach the drawbar to the bottom of the binder frame, having the plain end to the rear of the harvester. Attach the casting which is at the other end of the drawbar to the casting on the front part of the frame from which the harvester tongue was removed, using a bolt or slipping it on the pivot pin. The hole in this casting is reduced by removing the reducing ring, which should be done if necessary to accommodate the bolt or pivot. For nearly all makes of binders, however, the reducing ring should remain intact in the casting.

After the drawbar head is properly attached, loosen the bolt which holds the drawbar to the head and swing the rear end of the bar in the direction of the platform of the harvester, as far as fastening with the clip bolt will permit. Several different ways of attaching drawbar ends are shown in Figure 49.

Disconnect the cross section of the hitch from the tongue and receding bar by removing the bolts which connect them to the castings on the cross section bar. Connect the main casting No. 50 to drawbar head and end casting No. 5 I to the eye or lug from which the tongue brace was removed by means of a hook end bolt. See Figure 48 showing various position of bolt and casting. The casting No. $5 \mathrm{I}$ is so designed that the cross bar is on the level for most makes of harvesters, but for some kinds it will be found a trifle too high, and the casting should be turned bottom side up. The top side of the casting is the side which bears its number, and all castings are put on with the numbers up at the factory.

Connect the tongue and receding bar to the castings from which they were removed and tighten up the bolt which holds the drawbar to the drawbar head.

Set the steering rod support in a position slanting forward enough so that it will not come in contact with any part of the harvester frame or interfere with the tilting of the platform. See that all necessary adjustments of the reel can be made before the harvester is put in the field. The steering rod bearing can be raised or lowered and it should be set as low as the harvester frame will permit.

For each set of hitches will be found one hitch with a short tongue. This short tongue is to be used on binder which couples to engine.

There is more waste and inefficiency on the average farm than there is in the worst managed factory in the United States. Why? Because factory work, even when it is done badly, is done on right principles; and because farming, even when it is done well, is done on lines that are old-fashioned and out-grown. The main thing on the farm is still muscle-labor. Sweat of man and horse is still regarded as the best of all fertilizers.

Debt is still regarded by the average farmer as a calamity. His worst enemy is a mortgage, so he thinks. And his idea of prosperity is 500 acres of land operated by himself, five hired men and a herd of horses.

The manufacturer found out long ago that debt could be a man's best friend. Debt means capital, and capital means better equipment. The successful manufacturers of today are the men who dared to borrow money and build larger mills and larger factories. Andrew Carnegie, for instance, was always the biggest borrower in the state of Pennsylvania.

One hundred dollars costs only $\$ 6$ a year, while the cheapest workman costs $\$ 6$ a week. The cost of one cheap laborer equals the cost of $\$ 5,000$.

The manufacturer has learned this, but the farmer has not. That is why the manufacturer works short hours. That is why there is less sweat and more profits in the manufacturer's office. That is why the manufacturer, and not the farmer, is the money power of the United States.

Herbert N. Casson. 


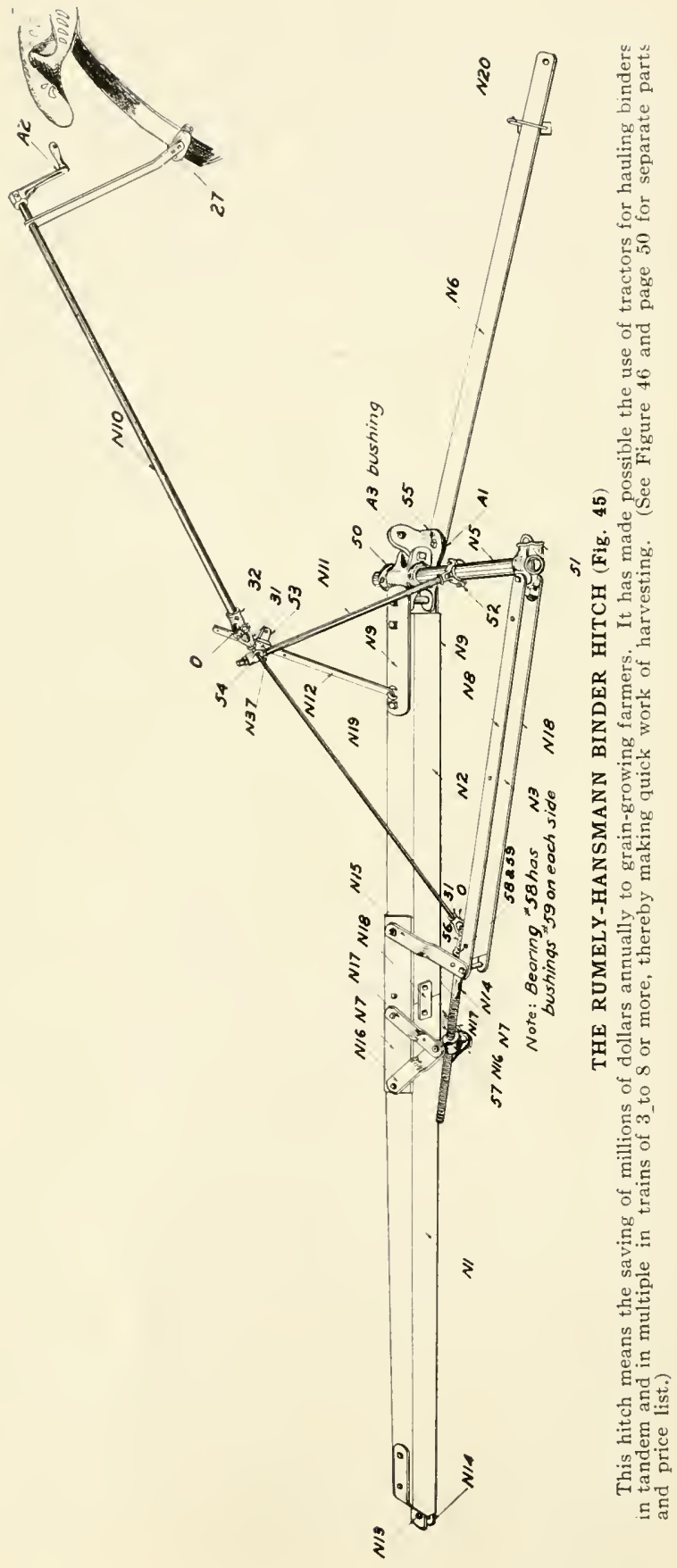



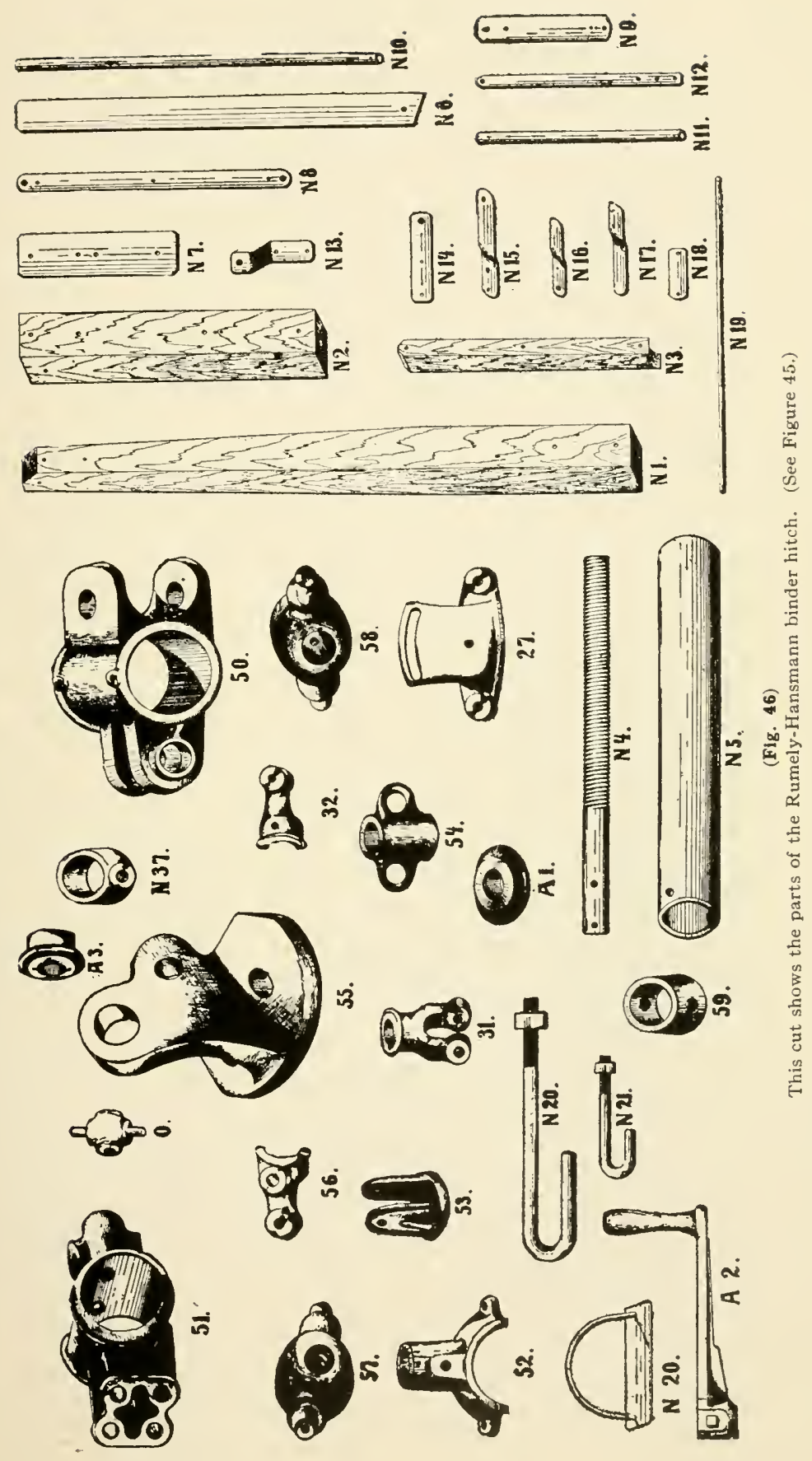


\section{Parts of the Rumely-Hansmann Binder Hitch}

Tongue.

Tongue Section

2. 50

Receding bar....

I. 50

Screw..

2. 50

Cross section pipe.

I . 00

Drawbar

2.50

Tongue section plate

I. 00

Receding bar strap..

I. .00

Main casting coupling iron

I. $\mathrm{OO}$

Horizontal steering rod. 50

Vertical steering $\operatorname{rod}$ support.................. . 50

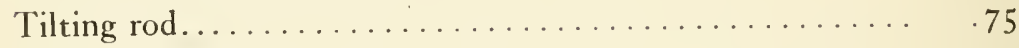

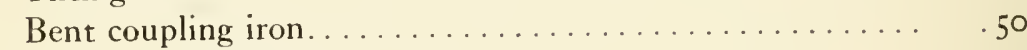

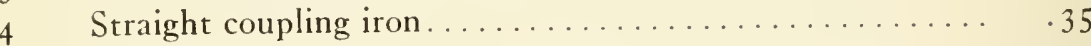

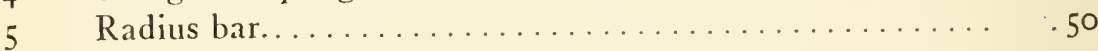

6 Screw nut support bar, short..................... 30

N 17 Screw nut support bar, long................. .75

N i8 Tongue section side plate...................... ${ }^{2} 25$

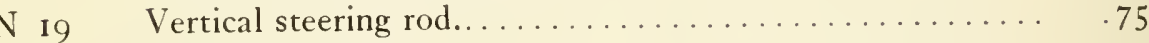

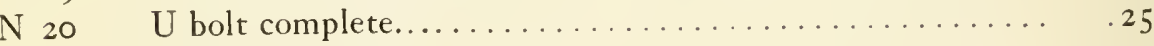

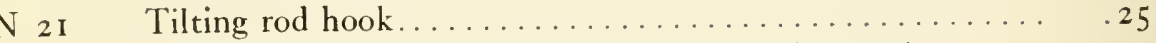

$\mathrm{N}_{22}$ Platform hook (Marked $\mathrm{N}_{20}$ in Figure 46 in error)....... ${ }_{2} 25$

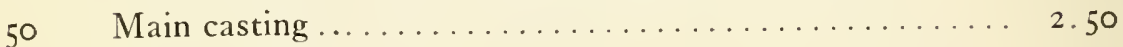

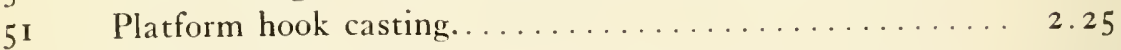

55 Drawbar head.......................... 1.50

3 Bushing for drawbar head ..................... .25

37 Set collar for vertical shaft bearing.................. .25

○ Knuckle center.......................... .75

$57 \quad$ Nut for screw............................. I.

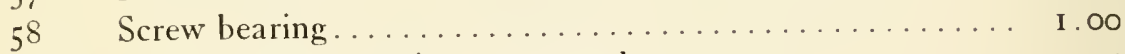

56 Universal joint casting, screw end............... .75

32 Universal joint casting, horizontal shaft end.......... 50

52 Foot for vertical shaft support................. I. 00

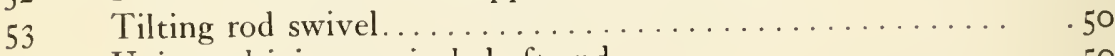

3 I Universal joint vertical shaft end................ .50

54 Vertical shaft bearing......................... 50

27 Seat post casting........................ I. 25

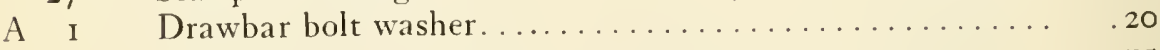

59 Collar for screw............................ 75

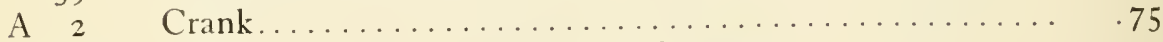

Complete attaching extras for McCormick harvesters.......... I. .

Complete attaching extras for Acme harvesters............. I. .

In ordering extras give name and number to facilitate prompt shipment. 


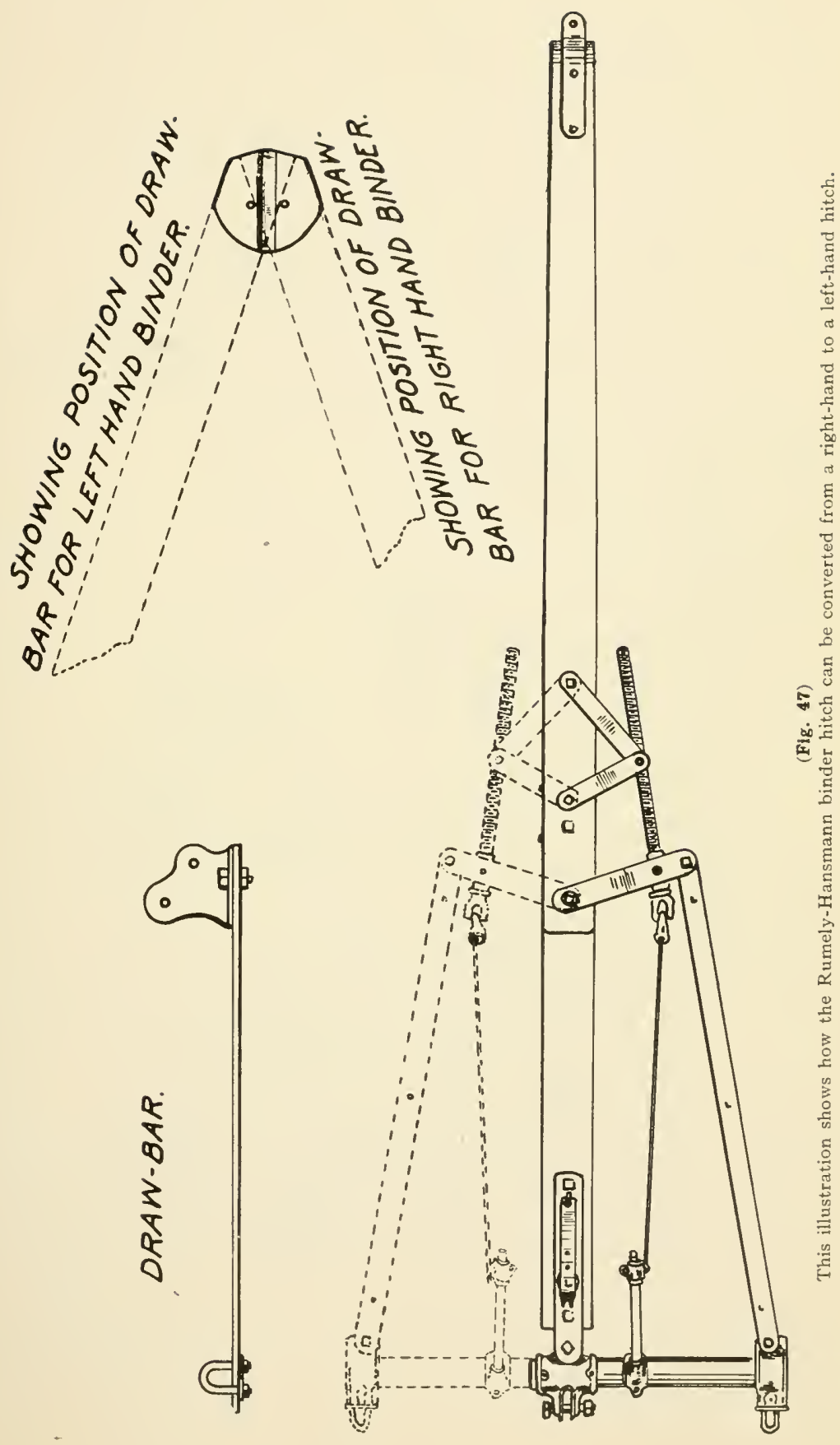


F/6.4.
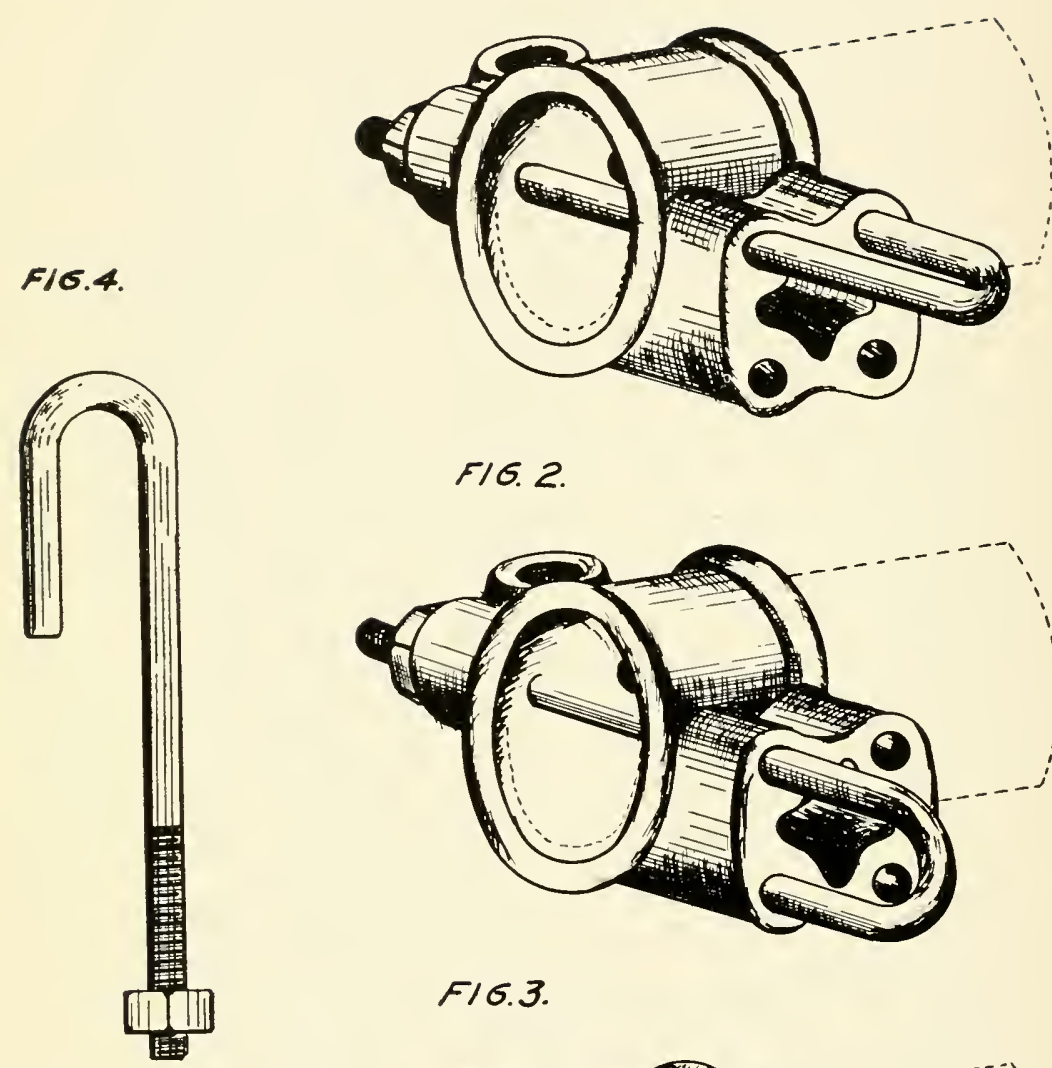

\section{FIG. 2 .}

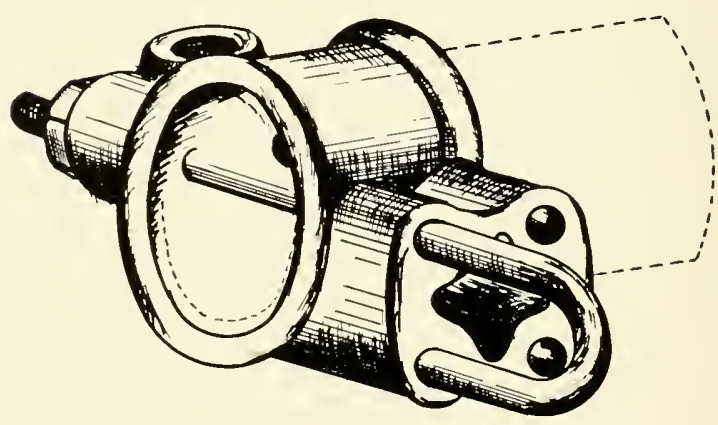

F/6.3.

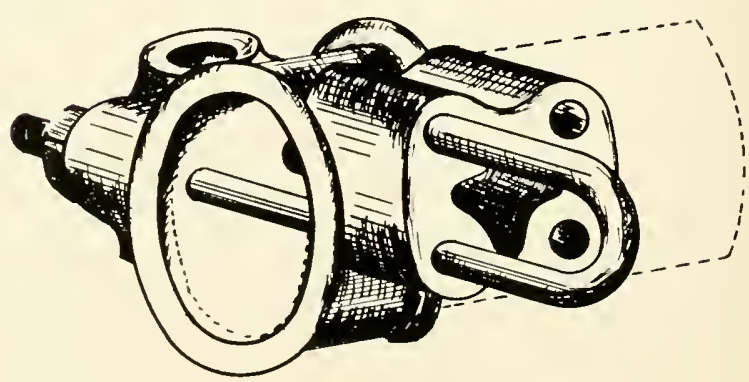

(Fig. 48)

This cut shows the many different ways in which the hook casting (No. 51 in Figures 45 and 46) of the Rumely-Hansmann Binder Hitch can be placed so as to accommodate the several makes of binders. 
ILLUSTAATION SHOWING

HOW DRAW-BAR ATTACHES TO REAR OF M! COPMICK BINDER

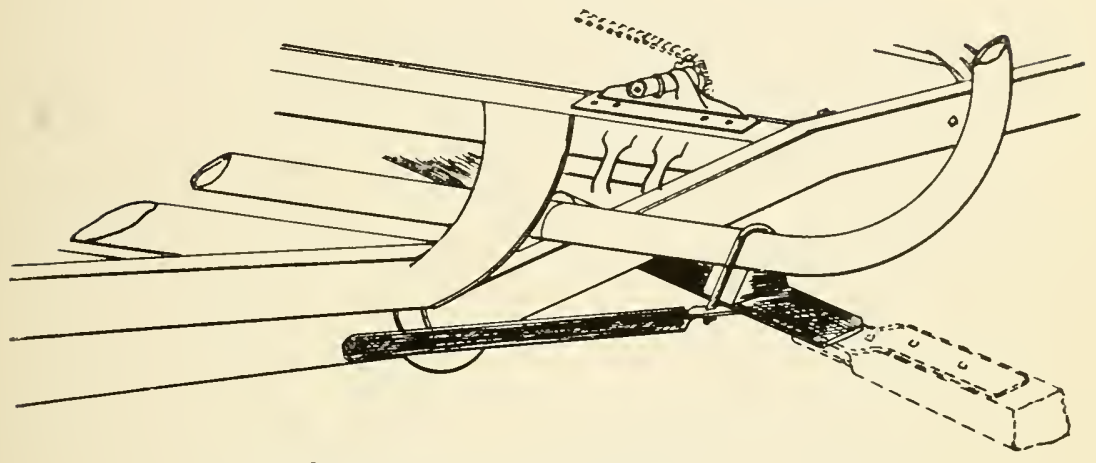

ILLUSTPATION SHOWING HOW DRAW-BAR ATTACHES TO PEAR OF ACME BINDER

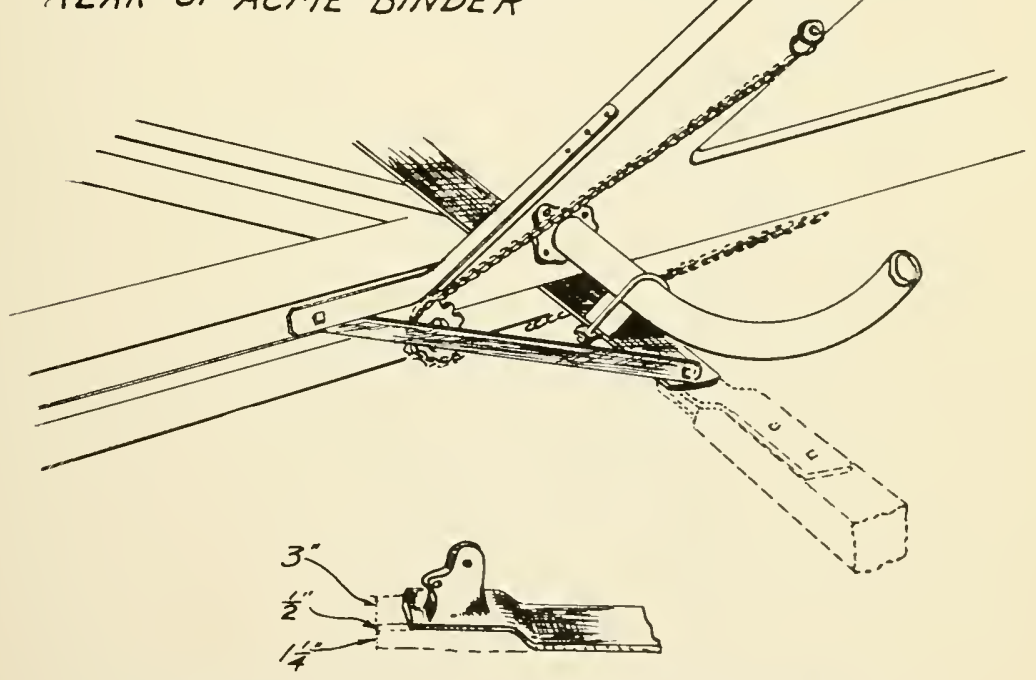

ILLUSTRATION SHOWING DRAW-BAR BENT TO FIT ACME BINDERS

(Fig. 49)

This cut shows how the drawbar of the Rumely-Hansmann Binder Hitch (Figure fi) is attached to the frames of McCormick and Acme binders. 


\section{RUMELY}

LA POR'TE

\section{Power-Farming Machinery}

\section{WHY IT EXCELS}

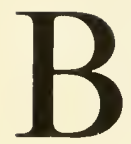

ECAUSE every machine in our line is built right-and is right in design, construction and materials. Built and backed by sixty years' experience in machinebuilding - their good qualities are absolutely assured and guaranteed. It would be poor business policy to let a single machine go out of our shops with the slightest blemish-and we don't do it. Each machine is inspected carefully before the final touches are put on.

More than this, Rumely service is unexcelled -we maintain 34 branches in the United States and 10 in Canada where machines and repairs are stocked and where complete information on any Rumely machine may be had upon request. The Rumely corps of salesmen and dealers is world-wide-Rumely fame is being spread throughout every country.

Before you buy, make sure that the machine bears the Rumely "World" trade-mark - an accepted proof of honest material and honest build. Follow the example of thousands who have already bought Rumely machines and stayed pleased. 

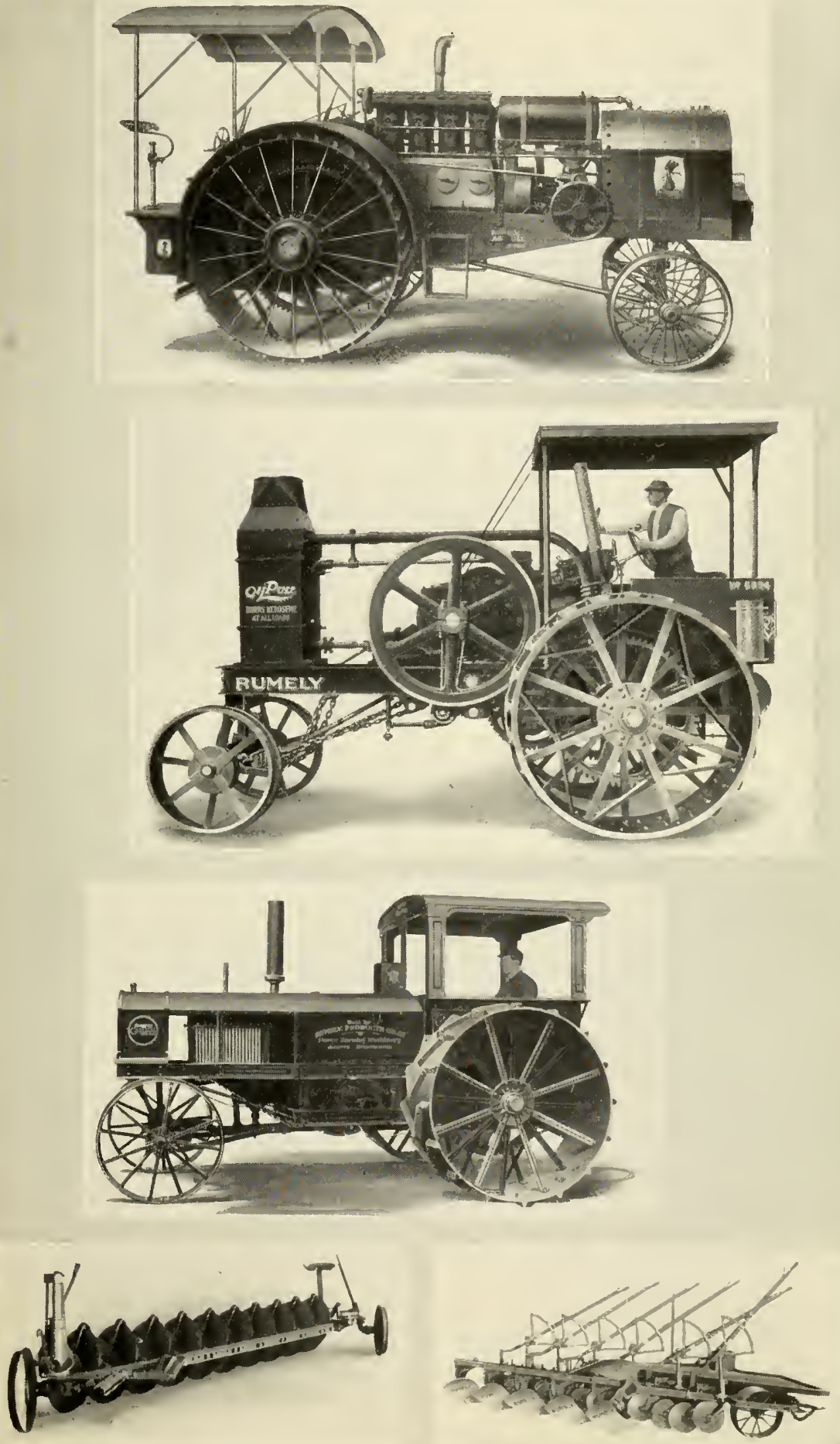


\section{Rumely Power-Farming Machinery}

\section{Sold all Over the World}

Rumely Products Co., Inc., maintain branches at each of the points named below. For complete information on any machine, just fill out the blanks (write plainly) and mail to the branch house nearest you. Your inquiry will receive immediate attention.

\section{UNITED STATES :}

Aberdeen, S. D.

Battle Creek, Mich,

Billings, Mont.

Bismarck, N. D.

Cedar Rapids, Ia.

Chicago, 111.

Columbus, Ohio

Dallas, Texas

Decatur, Ill.

Denver, Colo.

Des Moines, la.

\section{CANADA :}

Brandon, Man.

Calgary, Alta.

Edmonton, Alta.

Estevan, Sask.
Fargo, N. D.

Grand Forks, N. D.

Harrisburg, $\mathrm{Pa}$.

Houston, Texas

Indianapolis, Ind.

Kansas City, Mo.

LaPorte, Ind.

Lexington, Ky .

Lincoln, Nebr.

Los Angeles, Cal.

Madison, Wis.

Regina, Sask.

Saskatoon, Sask.

Toronto, Ont.
Minot, N. D.

Minneapolis, Minn.

Nashville, Tenn.

New Orleans, La.

Pocatello, Idaho

Portland, Ore.

St. Louis, Mo.

San Francisco, Cal.

Sioux Falls, S. D.

Spokane, Wash.

II ichita, Kas.

Vancouver, B. C.

Winnipeg, Man.

Yorkton, Sask.

\section{RUMELY PRODUC'TS CO.}

GENTLEMEN: Please send me literature and full information regarding the machines opposite which $I$ have made an $(X)$.

$\begin{aligned} & \square \text { Circulars } \\ & \square \text { OilPull Tractors } \\ & \square \text { GasPull Tractors } \\ & \square \text { ToeHold Tractors } \\ & \square \text { Steam Tractors } \\ & \square \text { Gasoline Engines } \\ & \square \text { Kerosene Engines } \\ & \square \text { Grain Separators } \\ & \square \text { Rice Separators } \\ & \square \text { Clover Hullers } \\ & \square \text { Engine Gang Plows } \\ & \square \text { Traction Disc Plows } \\ & \square \text { Engine Guides } \\ & \square \text { Oil and Water Tanks } \\ & \square \text { Silage Cutters }\end{aligned}$

I farm
Catalogs

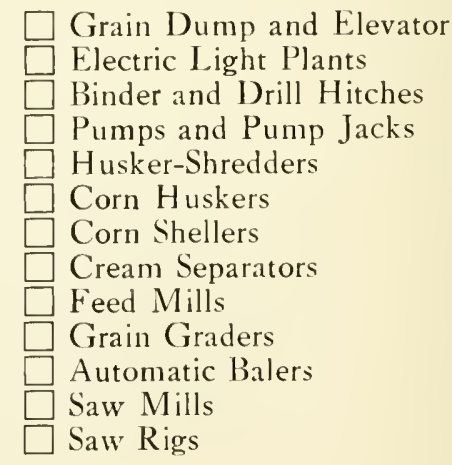

Name

Address

R.F. D.

Remarks.

acres. I use

horses. 

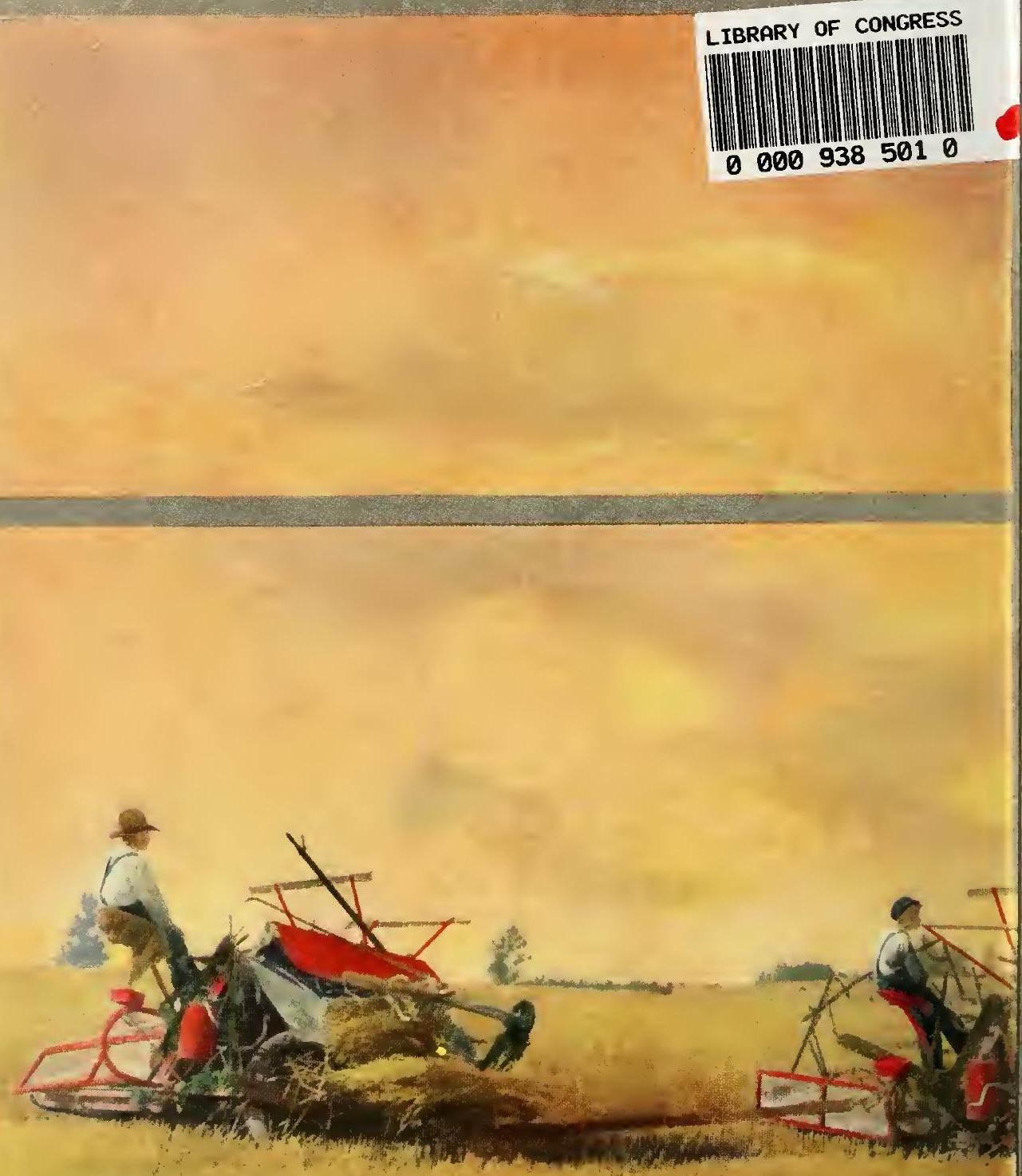